\title{
EM Algoritmasına Göre Kümelenen Havalimanlarının Borda Sayım Yöntemi İle Değerlendirilmesi
}

\section{Nuri ÖMÜRBEK ${ }^{1}$ Okan DAĞ $\breve{2}^{2}$ Hande EREN ${ }^{3}$}

\begin{tabular}{ccc}
\hline $\begin{array}{c}\text { Geliş Tarihi/ Received } \\
\text { 16/12/2019 }\end{array}$ & Kabul Tarihi/ Accepted & Yayın Tarihi/ Published \\
$09 / 03 / 2020$ & $15 / 04 / 2020$ \\
\hline Citation/Atıf: Ömürbek, N., Dağ, O., ve Eren, H., (2020), EM Algoritmasına Göre Kümelenen \\
Havalimanlarının Borda Sayım Yöntemi Ille Değerlendirilmesi, Atatürk Üniversitesi İktisadi ve \\
İdari Bilimler Dergisi, 34(2): 491-514, DOI: $10.16951 /$ atauniiibd.659125 \\
\hline
\end{tabular}

Öz: Kümeleme analizi veri tabanlarındaki verileri kümeler ya da gruplar içerisinde toplayarak birbirine benzer niteliklere sahip olan elemanların bir araya getirilmesinde kullanılan bir veri madenciliği yöntemidir. Bu çalışmada Türkiye' de yer alan 55 havalimanından verilerine eksiksiz olarak ulaşılan 49 havalimanının kümelenmesi amaçlanmıştır. Bu havalimanlarının kümelenmesinde; uçak sayısı, ticari uçak sayısı, yük miktarı, yolcu sayısı, satış gelirleri, hizmet giderleri, yolcuya hizmet verilen alan, yolcu terminalleri toplam alan, bilgi işlem cihaz sayısı, personel sayısı, kurtarma cihaz sayısı, hava ve radar seyrüsefer sistemleri, haberleşme telsiz cihazları, en yakın merkeze uzaklık, denizden yükseklik, hava sıcaklık ortalaması, yangınla mücadele kategorisi ve araç envanteri kriterleri kullanılmıştır. Çalışmada ilk önce ENTROPI yöntemi ile kriterlerin ağırlıkları hesaplanmış ve daha sonra kümeleme işlemi gerçekleştirilmiştir. Havalimanlarının kümelenmesinde EM algoritması kullanılmıştır. EM algoritmasına göre havalimanları 5 kümeye ayrılmıştır. Sonuç olarak elde edilen bu kümelerin BORDA Sayım yöntemi ile performans değerlendirmesi yapılmıştır.

Anahtar Kelimeler: Kümeleme, EM Algoritması, ENTROPI, BORDA Sayım Yöntemi, Havalimanı

Evaluatıon of Clustered Airports According to EM Algorithm by Borda Count Method

Abstract: Clustering analysis is a data mining method used to gather data from databases in clusters or groups and bring together elements having similar characteristics. In this study, Turkey 'is intended as a complete, well situated reached the airport on data from 55 of the 49 clusters airport. In the clustering of these airports; number of aircraft, number of commercial aircraft, amount of cargo, number of passengers, sales revenues, service expenses, passenger area, total area of passenger terminals, number of computing devices, number of personnel, number of rescue devices, air and radar navigation systems, communication radio devices, distance to the nearest center, height from sea, air temperature average, fire fighting category and vehicle inventory criteria were used. In this study, weights of the criteria were calculated by using

${ }^{1}$ Prof. Dr., Süleyman Demirel Üniversitesi, İktisadi ve İdari Bilimler Fakültesi, İşletme Bölümü, https://orcid.org/0000-0002-0360-4040

${ }^{2}$ Doktora Öğrencisi, Süleyman Demirel Üniversitesi, Sosyal Bilimler Enstitüsü, İşletme Bölümü, https://orcid.org/0000-0001-9756-722X

${ }^{3}$ Doktora Öğrencisi, Süleyman Demirel Üniversitesi, Sosyal Bilimler Enstitüsü, İşletme Bölümü, https://orcid.org/0000-0002-9166-5037 


\section{EM Algoritmasına Göre Kümelenen Havalimanlarının Borda Sayım Yöntemi İle Değerlendirilmesi}

ENTROPI method and then clustering process was performed. In the clustering of airports, EM algorithm which is one of the clustering algorithms is used. According to the EM algorithm, airports are divided into 5 clusters. As a result, the performance evaluation of these clusters was carried out by the BORDA Count method.

Keywords: Clustering, EM Algorithm, ENTROPI, BORDA Count Method, Airport

\section{EXTENDED SUMMARY}

Aim of the study: The aim of this study is to cluster 49 airports located in Turkey by using EM algorithm.

Literature Review: Some studies in the literature related to clustering analysis and clustering of airports are examined in the paper. Studies such as Use of Clustering Analysis in Family Psychology Research (Henry, Tolan \& Smith, 2005: 121-132), Location analysis (Barreto et al., 2007: 968-977), Clustering Gene Data (Jiang, Tang \& Zhang, 2004: 1370-1386 ), Clustering the Countries by K-Means and K-Medoids Segmented Clustering Algorithms (Sarıman, 2011: 192-202), Classification of OECD Countries with Fuzzy Clustering Analysis based on Health Indicators (Alptekin and Yeşilaydın, 2015: 137-155) were given examples of the studies on clustering in the paper.

When the studies on clustering of airports are examined; Strategically Clustering of Airports based on Common Atributes (Malighetti, Paleari and Redondi, 2009: 183-196), Comparison of Passenger Terminal Facilities of Airports by using Clustering Analysis (Adikariwattage, Barros, Wirasinghe \& Ruwanpura, 2012: 36-41), Using K-Means Method for Clustering Airports operating in Turkey (Yalçın and Ayyýldýz, 2018: 194-205) have been given as recent examples of the studies in the literature.

The inclusion of more criteria in more details into the study as well as the use of the WEKA program for the analysis are the major the differences of this study from the early studies in the literature. Moreover, ranking the clusters from the best to the worst by using the BORDA Counting method reveals the other difference and originality of the study.

Methodology: In the study, the number of aircrafts, the number of commercial aircrafts, the amount of freight, the number of passengers, sales revenue, service expenses, the size of the area served to the passengers, size of the total area of passenger terminals, the number of computing devices, the number of personnel, the number of rescue devices, air and radar navigation systems, wireless communication devices, distance to the nearest living center, altitude, average temperature, firefighting category and vehicle inventory criteria are considered for clustering 49 airports located in Turkey by using WEKA program. The data from 2013-2018 period are extracted from the State Airports Authority (DHMI) database for the analysis. The results assert that the EM algorithm provides the best results. The clusters found in the study were ranked by BORDA Counting Method from the best to the worst.

Conclusion and Discussion: Although there are 55 airports located in Turkey, this study includes only 49 of them that provides complete data for the 
study. The findings of the clustering analysis highlight that the Istanbul Atatürk Airport located in Cluster 0 is clearly distinguished from other clusters in terms of the number of aircrafts, the number of commercial aircrafts, the number of passengers, sales revenue, the areas served to passengers, size of the total area of passenger terminals, the number of computing devices, the number of personnel, the number of rescue devices, air and radar navigation systems, wireless communication devices, distance to the closest living center, altitude and vehicle inventory. All of the airports in Cluster 1 are located in the metropolitan cities. The airports in Cluster 3 and Cluster 4 are airports that are not very active compared to Cluster 0 and Cluster 1.

Finally, even though the airports located in Cluster 2 rank high in terms of service expenses, air and radar navigation systems, distance to the nearest living center and attitude, it ranks low in other criteria. BORDA Counting method was applied to test the partial reliability of the study and evaluate the performance of the clusters. The results of the BORDA Counting method show that "Cluster 0" takes the first place; "Cluster 1" is the second, "Cluster 4" is the third, "Cluster 3" is the fourth and finally "Cluster 2" is the fifth. When the results of the BORDA Counting method were compared with the findings of the clustering analysis of the WEKA program, it was seen that the results obtained were consistent.

\section{Giriş}

Günümüzde ulaşım, istenilen bir yere kısa sürede gitmek, bir gereksinim olmaktan çok zorunluluk gibi görülmektedir. Bundan dolayı havayolu ile ulaşım daha çok rağbet görmekte ve havayolu ulaşımını kullananların sayısı her geçen gün artış göstermektedir. Günümüzde toplumlar artık "hız" endeksli yaşam tarzına göre hareket etmektedir. Bu durum neticesinde de havalimanlarının önemi artış göstermektedir. Teknolojinin her geçen gün gelişim göstermesi ulaşım sektörünün gelişimi ile beraber havalimanlarının toplumların büyüme ve gelişmesinde çok büyük bir etken olduğu gerçektir. Hızlı ulaşımın yanında yurt içerisinde, bölgesel ve uluslararası ekonomilerin gelişim göstermesinde kayda değer katkıları bulunmaktadır. Ülkemizde de havalimanlarının önemi gün geçtikçe önem kazanmakta ve daha çok insana hizmet vermektedir (Turan ve Turan, 2008: 161).

Havayolu güvenli, hızlı ve konforlu bir ulaşım sağlayarak çeşitli coğrafyaların birbirine daha çok yakınlaşmasına imkân sağlamıştır (Gökdalay ve Evren, 2009: 159). Ekonominin büyümesi ile beraber artış gösteren talebin karşılanabilmesi amacı ile havalimanlarının sayısının fazlalaştırılması, mevcut havalimanlarının daha fazla verimli ve aktif çalışmasını zorunlu hale getirmiştir. Havalimanları, il ve ilçelerin gelişim göstermesine de kayda değer bir şekilde destek olmaktadir.

Yapılan bu çalışmada ilk olarak kümeleme analizi, havalimanları ve WEKA programı ile ilgili literatür taraması yapılmış; ardından kümeleme analizi yönteminin teorisine yer verilmiştir. Son olarak yapılan denemeler sonucunda 


\section{EM Algoritmasına Göre Kümelenen Havalimanlarının Borda Sayım Yöntemi İle}

Değerlendirilmesi

kümeleme analizi için en iyi sonucu EM algoritmasının verdiği görülmüştür. Kümeleme analizi için; uçak sayısı, ticari uçak sayısı, yük miktarı, yolcu sayısı, satış gelirleri, hizmet giderleri, yolcuya hizmet verilen alan, yolcu terminalleri toplam alanı, bilgi işlem cihaz sayısı, personel sayısı, kurtarma cihaz sayısı, hava ve radar seyrüsefer sistemleri, haberleşme telsiz cihazları, en yakın merkeze uzaklık, denizden yükseklik, hava sicaklık ortalaması, yangınla mücadele kategorisi ve araç envanteri olmak üzere 18 kriterden yararlanılmıştır. Bu kriterler kullanılarak 49 havalimanı kümelere ayrılmıştır.

\section{Literatür İncelemesi}

Literatür incelemesinde kümeleme ve havalimanlarının kümelenmesi ile ilgili yapılan bazı çalışmalara aşă̆ıda yer verilmiş̧tir.

Tablo 1: Kümeleme Analizi ve Havalimanları İle İlgili Literatür Özeti

\begin{tabular}{|l|l|}
\hline \multicolumn{2}{|c|}{ Kümeleme Analizi ile Yapılan Bazı Çalışmalar } \\
\hline $\begin{array}{l}\text { Aile Psikolojisi Araştırmalarında Kümeleme } \\
\text { Analizinin Kullanımı }\end{array}$ & (Henry, Tolan ve Smith, 2005: 121-132) \\
\hline Kuruluş Yeri Problemi & (Barreto vd., 2007: 968-977) \\
\hline $\begin{array}{l}\text { Ülkeler Arasındaki Ekonomik Benzerliklerin } \\
\text { Belirlenmesi }\end{array}$ & (Turanlı, Özden ve Türedi, 2006: 95-108) \\
\hline $\begin{array}{l}\text { Gen Verilerinin Kümelenmesi } \\
\text { Öğretmen Adaylarının Teknolojiye Yönelik } \\
\text { Tutumlarının Kümelenmesi }\end{array}$ & (Çelik ve Kahyaoğlu, 2007: 571-586) \\
\hline $\begin{array}{l}\text { OECD’e Üye Ülkelerin Bazı Seçilmiş Sağlık } \\
\text { Göstergelerinin Karşllaştırılmasında Kümeleme } \\
\text { ve Ayırma Analizlerinin Kullanılması }\end{array}$ & (Ersöz, 2009: 1650-1659) \\
\hline $\begin{array}{l}\text { Korelasyon Matrisinin İstatistiksel Belirsizliğinde } \\
\text { Kümeleme Analizinin Kullanımı }\end{array}$ & (Tola, Lillo, Gallegati ve Mantegna, 2008: \\
\hline $\begin{array}{l}\text { Faktör Analizi ve Aşamalı Kümeleme Analizi } \\
\text { Tekniklerinin Benzer Sonuç Verip Vermediğinin } \\
\text { Belirlenmesi }\end{array}$ & (Doğan ve Başokçu, 2010: 65-71) \\
\hline $\begin{array}{l}\text { K-Means ve K-Medoids Bölümlemeli Kümeleme } \\
\text { Algoritmalarıyla Ülkelerin Özelliklerine Göre } \\
\text { Kümelenmesi }\end{array}$ & (Sarıman, 2011:192-202) \\
\hline $\begin{array}{l}\text { OECD Ülkelerinin Sağlık Göstergeleri Açısından } \\
\text { Bulanık Kümeleme Analizi İle Sinıflandırılması }\end{array}$ & (Alptekin ve Yeşilaydın, 2015: 137-155) \\
\hline \multicolumn{2}{|c|}{ Havalimanlarının Kümelenmesi ile İlgili Yapılan Bazı Çalışmalar } \\
\hline $\begin{array}{l}\text { Havalimanlarının Ortak Özellikleri Doğrultusunda } \\
\text { Stratejik Olarak Kümelenmesi }\end{array}$ & (Malighetti, Paleari ve Redondi, 2009: 183- \\
\hline $\begin{array}{l}\text { Havalimanlarında Yolcu Terminali Olanaklarının } \\
\text { Kümeleme Analizi İle Karşılaştırılması }\end{array}$ & (Adikariwattage, Barros, Wirasinghe ve \\
\hline $\begin{array}{l}\text { K-Ortalamalar Yöntemi İle Türkiye'de Faaliyet } \\
\text { Gösteren Havalimanlarının Kümelenmesi }\end{array}$ & (Yalçın ve Ayyıldız, 2018: 194-205) \\
\hline
\end{tabular}

Havalimanları ile ilgili yapılan çalışmalar incelendiğinde genellikle kriterlerin eşit öneme sahip olduğu düşünülmüştür. $\mathrm{Bu}$ çalışmada ise havalimanlarıyla ilgili yapılmış olan diğer çalışmalardan farklı olarak mevcut durumda bulunan kriterlerin eşit önem derecesine sahip olmadığ düşünülmüş ve ilk olarak ENTROPİ yöntemiyle kriter ağırlıkları belirlenmiştir. Daha sonra bu 
kriter ağırlıkları karar matrisinde yer alan değerlerle çarpılarak WEKA programına aktarılmıştır. Bununla birlikte kümeleme analizi ile elde edilen kümelerin BORDA Sayım yöntemiyle sıralanması da bu çalışmanın literatürdeki çalışmalardan farklılığını gösteren diğer bir özgünlüğüdür. Bunun yanında çalışmada kullanılan kriterler literatürdeki diğer çalışmalara göre daha kapsamlı olarak ele alınmıştır.

\section{Kümeleme Analizi}

Kümeleme analizi elde bulunan mevcut durumdaki verilerin gruplaması işlemi sırasında yararlanılan bir sınıflandırma tekniğidir. Kümeleme analizinin amacı, gruplara ayrılmamış verileri benzerlikler baz alınarak sınıflandırmak ve kullanacak olan kişiye yararlı olacak bilgiler ortaya koymaktır. Kümeleme analizi, birçok alanda yaygın bir şekilde kullanılan çok değişkenli bir istatistik tekniktir (Çelik, 2013: 175).

Kümeleme analizi, grup sayısı önceden belli olmayan ve gruplara ayrılmamış verilerin benzerliklerine göre sınıflandırılması amaciyla kullanılmaktadır. Kümeleme analizi; birbirine benzer olan nesneleri aynı gruplarda bir araya getirmeyi amaçlaması açısından diskriminant analizi ile, birbirine benzer değişkenlerin benzer gruplar altında bir araya getirilmesini amaçlaması nedeniyle de faktör analizi ile benzerlik göstermektedir (Çakmak, 1999: 188).

Literatüre bakıldığında kümeleme tekniklerini $\mathbf{5}$ ana başlık altında toplamak mümkündür.

\subsection{Hiyerarşik Kümeleme Teknikleri}

Hiyerarşik kümeleme yöntemleri, birimleri farklı adımlar uygulandıktan sonra bir araya getirerek; ardışık bir şekilde kümeler meydana getirmeye ve aynı zamanda bu kümelere atanacak nesnelerin hangi uzaklık veya benzerlik seviyesinde küme elemanı olduğunu ortaya koymaya yönelik tekniklerdir.

Hiyerarşik kümeleme yöntemleri, araştırmacı tarafından araştırılan veri grubunda kaç grup olduğu bilinmediği durumlar karşında oldukça elverişli bir teknik olarak görülmektedir. Yöntem araştırmacıya ele aldığı veri grubunda daha önce gözlemlenmemiş ilişkileri analiz etme imkânı tanımasından dolayı da oldukça yarar sağladığı bilinmektedir (Anderberg,1973: 22).

Hiyerarşik kümeleme yöntemlerinden literatürde en çok kullanılan tekniklerden bazıları Tam Bağlantı Kümeleme Algoritması, Tek Bağlantı Kümeleme Algoritması, Ortalama Bağlantı Kümeleme Algoritması, Merkez Bağlantı Kümeleme Algoritması, Ward Kümeleme Algoritması'dır.

\subsection{Yoğunluğa Dayalı Kümeleme Yöntemi}

Yoğunluğa dayalı kümeleme tekniklerinde uzaklığa dayalı küme seçimi yerine verilerin yoğunluk durumuna göre kümeleme işlemi yapılmaktadır. Bu tekniklerde, kümeler veri tabanındaki daha yüksek yoğunluklu alanlar şeklinde ifade edilmektedir (Ester vd., 1996: 227). 
EM Algoritmasına Göre Kümelenen Havalimanlarının Borda Sayım Yöntemi İe Değerlendirilmesi

Algoritmanın nasıl çalıştığını daha iyi ifade edebilmek için algoritmanın bazı özellikleri aşağıda verilmiştir (Ye vd., 2003: 345-346).

- Herhangi bir p noktasının Eps değeri MinPts değerinden daha çok veriye sahipse kümenin yeni merkezi bu p değeri olacaktır.

- Ele alınan bir veri merkez noktada bulunmuyorsa sınır değer olacaktır. Buradaki sınır değer diğer bir merkez noktası için yoğunluğa katılabilir özelliktedir.

- Bir p noktası q noktasının yoğunluğuna katılabilir özellikteyse; bu durum $p_{1}=q$ ve $p_{n}=p$ şartlarında ve $p_{1}, . ., p_{n}$ nesnelerinde zincirleme ise $p_{i+1}$ nesnesi de yoğunluğa dahil edilmiş olacaktır (Borah ve Bhattacharyya, 2004: 92).

- Eğer yukarıda anlatılan maddelere uygun herhangi bir veri bulunmuyorsa yani tek kalmış bir veri varsa, bu veri gürültü olarak ifade edilmektedir.

Literatürde en fazla kullanılan yoğunluğa dayalı kümeleme algoritmaları; DBSCAN, OPTICS ve DENCLUE algoritmalarıdır.

\subsection{Bölümleyici Kümeleme Algoritmaları}

Veri madenciliği algoritmalarından biri olan bölümleyici kümeleme algoritmaları veri kümesinden $\mathrm{n}$ tane giriş parametre kabul eden ve bu parametreleri k tane kümeye bölen algoritmalardır. Merkez noktaların kümeyi temsil etmesi esasına dayanan bölümleyici kümeleme algoritmaları kolay uygulanabilir olması ve verimli sonuçlar vermesi nedeniyle sıklıkla kullanılmaktadır. (Alzand ve Karacan, 2014: 57).

Bölümleyici kümeleme algoritmalarında kümeler, mesafeye dayalı bir farklı1ık fonksiyonu gibi objektif bölümleme kriterini optimize etmek için oluşturulmuştur. Böylelikle bir küme içindeki nesneler benzer olurken, farklı kümelerin nesneleri veri kümesi özellikleri bakımından birbirinden farklıdır (Han ve Kamber, 2006: 401).

Bölümleyici kümeleme algoritmalarında ilk olarak $\mathrm{k}$ sayısına göre başlangıç kısmı meydana getirilir. Küme içi benzerliklerin aynı kalmasına ya da belirli bir iterasyon miktarına kadar nesneler, yer değiştirme ile bölümler arası geçişlerde bulunabilir. Bölüm içi benzerlik ne kadar fazla ve bölümler arasındaki mesafe ne kadar çok ise başarılı bir kümeleme işleminden bahsedilebilir (Tekbir, 2009: 14).

$\mathrm{Bu}$ algoritmalar arasında yaygın olarak kullanılanlar k-ortalama, kmedoid, CLARA ve CLARANS algoritmalarıdır.

\subsection{Izgara Temelli Kümeleme Algoritmalart}

Izgara tabanlı kümeleme algoritmalarında, veri alanı 1zgaralar olarak bilinen sınırlı sayıda eşit alan hücrelerine ayrılmakta ve sonrasında birbirine yakın durumda bulunan izgaraların noktalarını gruplara ayırmak adına bu ızgaralar üzerinde topolojik komşu arama işlemi yapılmaktadır. Izgara tabanlı kümeleme algoritmaları, literatürde yer alan diğer kümeleme algoritmalarıla kıyaslandığında daha hızlı işlem süresine sahip olduğu görülmektedir. Bunun nedeni olarak ise 1zgara temelli kümeleme algoritmalarında tüm kümeleme 
işlemleri, veri nesneleri yerine 1zgara hücrelerinde gerçekleştirilmesi gösterilmektedir.

Izgara Tabanlı Kümeleme Algoritmas1, bir 1zgara hücresi kümesi tanımlayarak, ele alınan elemanları uygun ızgara hücresine atamaktadır. Böylece her bir hücrenin yoğunluğunu hesaplayarak ve yoğunluğu tanımlanmış bir eşiğin altında kalan hücreleri elemektedir. Daha sonra 1zgara temelli kümeleme algoritmaları bitişik yoğun hücre gruplarından kümeler meydana getirmektedir. Izgara tabanlı kümeleme algoritması, çoklu çözünürlüklü ızgara veri yapısını kullanmaktadır. Kümeleme karmaşıklı̆̆ı, veri kümesindeki elemanların sayısına değil, doldurulmuş 1zgara hücrelerinin sayısına bağlıdır. (Suman ve Rani, 2017: 1510-1511).

Bu algoritmanın en önemli avantajı, özellikle çok büyük veri kümelerinin kümelenmesinde hesaplama karmaşıklığını azaltmaktır. Yaygın bir şekilde kullanılan Izgara Tabanlı kümeleme yöntemlerinden bazıları STING, WaveCluster, CLIUQE' tir (Bano ve Khan, 2018: 135).

\subsection{Olasıllk Temelli Kümeleme Algoritması}

Olasılık modeline dayalı kümeleme yöntemleri, el yazısı tanıma, doküman kümeleme işlemine kadar pek çok alanda aktif bir biçimde yararlanılmaktadır. Modele dayalı kümeleme teknikleri olasılık yaklaşımlarından yararlanarak gözlenen verilerle, bazı matematiksel modeller arasındaki uyumu maksimum duruma getirmektedir. Bazı yöntemler, genellikle verinin ilgili olasılık dağılımlarının karmasından meydana gelmektedir. Uygulamada her bir küme parametrik olasılık dağılımları ile matematiksel bir şekilde ortaya konmaktadır. Bundan dolayı kümeleme problemi saf bir parametre öngörü problemine evrilmektedir. Bu sayede veri, $K$ karmaşık yapıda bileşen dağılımları ile modellenebilmektedir (Servi, 2009: 85-86).

Olasılık tabanlı kümeleme algoritmalarından en çok kullanılan algoritma ise EM algoritmasidır.

\section{Metodoloji}

Bu bölümde çalışmada kullanılan; ENTROPI Yöntemi, EM Algoritması ve BORDA Sayım Yöntemlerine ilişkin bilgi verilmiştir.

\subsection{ENTROPI Yöntemi}

Entropi kavramı, ilk defa 1865 yılında Rudolf Clausius tarafindan ileri sürülmüştür. $\mathrm{Bu}$ kavram termodinamikte dağınıklık ve düzensizliğin bir göstergesi olarak bilinmektedir. Termodinamiğin ikinci yasası olarak kabul edilen Entropi terimi evrende kendi kendine, doğal şartlara bırakılan bütün sistemlerin günden güne, düzensizliğe, dağınıklığa ve bozulmaya doğru gideceğini varsayar. Entropi kavramı, Shannon (1948) tarafından alışılmışın dışında bir kullanıma gelerek enformasyon Entropisi halini almıştır. Bu teoriye göre Entropi rassal değişkenlerle ilgili belirsizliğin ölçüsüdür (Zhang vd., 2011: 444). 
EM Algoritmasına Göre Kümelenen Havalimanlarının Borda Sayım Yöntemi İle Değerlendirilmesi

Entropi Yöntemi 4 adımdan meydana gelmektedir (Karami ve Johansson, 2014: 523-524, Wang ve Lee, 2009: 8982):

Adım 1: Karar matrisinde birbirinden farklı indeks boyutlarının eşölçülemezlik üzerindeki etkilerini yok etmek için indeksler birbirinden farklı yöntemlerle standartlaştırılabilmektedir. Kriterler fayda ve maliyet indekslerine göre eşitlik (1) ve eşitlik (2) ile normalize edilir.

$$
\begin{array}{ll}
r_{i j}=x_{i j} / \max _{i j} & (i=1 \ldots, \mathrm{m} ; J=1, \ldots, \mathrm{n}) \\
r_{i j}=\min _{i j} / x_{i j} & (i=1 \ldots, \mathrm{m} ; J=1, \ldots, \mathrm{n})
\end{array}
$$

Adım 2: Birbirinden farklı ölçü birimlerindeki aykırılıkları ortadan kaldırmak amacıyla normalizasyon yapılarak eşitlik 3'de görüldüğü gibi $P_{i j}$ hesaplanir.



$i$ : alternatifler,

$j$ : kriterler

$p_{i j}$ : normalize edilmiş değerler

$a_{i j}$ : verilen fayda değerleri

Adım 3: 3. adımda $E_{j}$ 'nin entropisi eşitlik (4) ile hesaplanır.

$$
\begin{gathered}
E_{j=}-k \sum_{i=1}^{m}\left[P_{i j} \ln P_{i j}\right] ; \forall_{j} \\
\mathrm{k}:(\ln (n))^{-1}
\end{gathered}
$$

k: entropi katsayısı

$E_{j}$ : entropi değeri

$P_{i j}:$ normalize edilmiş değerler

Adım 4: Bu adımda $d_{j}$ belirsizliği eşitlik (5) ile hesaplanır.

$$
d_{j}=1-E_{j} ; \forall_{j}
$$

Adım 5: Eşitlik (6) kullanılarak j kriterinin önem derecesi yani $w_{j}$ ağıllıkları hesaplanır.

$$
w_{j}=\frac{d_{j}}{\sum_{j=1}^{n} d_{j}} ; \forall_{j}
$$

\subsection{EM (Expectation Maximization) Algoritmast}

EM (Expectation Maximization-Beklenti Maksimizasyonu) Algoritması bir nesnenin hangi küme içerisinde olacağını belirlemeye yönelik net mesafe kıstaslarından yararlanmak yerine tahminsel ölçütlerden yararlanmayı tercih etmektedir.

Maksimum benzerlik ilkesine dayanan Beklenti Maksimizasyonu (BM) algoritması ilk olarak Dempster ve arkadaşları tarafından 1977 yılında 
geliştirilmiştir. Regresyon atamasının yineleme süreçli bir şeklidir ve iki yinelemeli adımdan meydana gelmektedir.

EM algoritması son dönemde pek çok çalışmada yararlanılan yaygın bir yaklaşım haline gelmiştir. EM algoritması, eksik veri problemlerini çözmek adına maksimum olasılık öngörülerini yapan yinelemeli bir algoritmadır. EM Algoritmasının her tekrarı iki adımdan meydana gelmektedir. Bu adımlar, bekleneni bulma (E-Adımı) ve maksimize etme (M Adımı) olarak isimlendirilmektedir (Baygül, 2007: 14-15).

E-adımında gözlemlenen verilerin parametrelerine dair kestirimlerden yararlanılarak bilinmeyen (kayıp) veri ile ilgili en iyi olasılıklar tahmin edilirken, M-Adımında ise tahmin edilen kayıp veri yerine konulan bütün veri üzerinden maksimum olabilirlik hesaplanarak parametrelerin yeni kestirimleri elde edilmektedir (Bruzzone ve Prieto, 2002: 453-455).

\subsection{BORDA Sayım Yöntemi}

Birden fazla teknikten yararlanarak en iyi seçeneğin bulunabilmesi adına yapılmış olan bir tür etkinlik kıstası şeklinde ifade edilebilmektedir. BORDA Sayım yöntemi de birden fazla yöntemden yararlanılarak meydana getirilmiş sıralamaları bir araya getirerek tek bir sıralama ortaya koymaktadır. Sosyal seçim teorisindeki oylama tekniklerinden olan BORDA Sayım yöntemi Jean-Charles de Borda tarafından ortaya atılmışıı. Modern seçim tekniklerinin gelişmesinde kayda değer ölçüde payı bulunan BORDA Sayım yöntemi alternatifleri karar vericilerin bireysel tercihlerinin toplamına göre sıralamayı amaçlayan bir yöntem şeklinde ifade edilmektedir (Wu, 2011: 12974).

Sınıflama performansı için her bir grubu eşit önem derecesinde kabul eden BORDA sayım yöntemi uygulanma bakımından da basit bir yöntemdir (Ho, Hull ve Srihari, 1992: 85). Üzerine çalışılan grup içerisinde yer alan $m$ adet seçenekten en iyi durumda bulunan seçeneğe $\mathrm{m}-1$, ikinci sırada en iyi durumda bulunan seçeneğe m-2 olacak şekilde gittikçe birer azalan değerler verilerek ve en kötü seçenek 0 değerini alacak biçimde puanlama sistemi uygulanmaktadır. Tüm bunlara ek olarak tüm sınıflardaki seçenekler için atanan değerler toplanarak BORDA sayım yönteminin skoruna ulaşılır ve sıralama bu değer üzerinden yapılmaktadır. Yapılan bu sıralamayla ilgili matematiksel gösterim eşitlik 7'de görülmektedir (Lansdowne ve Woodward, 1996: 27):

$\mathrm{b}_{(\mathrm{i})}=\sum_{k=1}^{n}\left(M-r_{i k}\right)$

$\mathrm{r}_{\mathrm{ik}}: \mathrm{k}$. kriter altındaki i. alternatifin sıras1,

M: Toplam alternatif sayısıdır.

\section{Türkiye'deki Havalimanlarının EM Algoritması ile Kümelenerek Borda Sayım Yöntemi ile Değerlendirilmesi}

Çalışmanın bu bölümünde; uçak sayısı, ticari uçak sayısı, yük miktarı, yolcu sayısı, satış gelirleri, hizmet giderleri, yolcuya hizmet verilen alan, yolcu terminalleri toplam alan, bilgi işlem cihaz sayısı, personel sayısı, kurtarma cihaz 
EM Algoritmasına Göre Kümelenen Havalimanlarının Borda Sayım Yöntemi İe Değerlendirilmesi

sayısı, hava ve radar seyrüsefer sistemleri, haberleşme telsiz cihazları, en yakın merkeze uzaklık, denizden yükseklik, hava sıcaklık ortalaması, yangınla mücadele kategorisi ve araç envanteri kriterlerinden yararlanılarak Türkiye'de yer alan 49 havalimanının kümelenmesi amaçlanmıştır.

Çalışmada kullanılan veriler 2013-2018 yıllarına ait olup; Devlet Hava Meydanları İşletmesi (DHMI)' nden alınmıştır.

Havalimanlarının kümelenmesinde WEKA programında yer alan algoritmalardan yararlanılarak kümeleme analizi yapılmıştır. Yapılan kümeleme analizi sonucunda elde edilen kümelere bakıldığında en iyi sonucu EM algoritmasının verdiği görülmüştür. Çalışmada kümeleme analizi sonucunda elde edilen kümelerin BORDA Sayım Yöntemi ile en iyiden en kötüye doğru sıralanması amaçlanmıştır.

Tablo 2: Kriterler ve Gösterge Kodları

\begin{tabular}{|c|l|c|l|}
\hline $\begin{array}{c}\text { Gösterge } \\
\text { Kodları }\end{array}$ & \multicolumn{1}{|c|}{ Kriterler } & $\begin{array}{c}\text { Gösterge } \\
\text { Kodlar }\end{array}$ & \multicolumn{1}{|c|}{ Kriterler } \\
\hline K1 & Uçak Sayıs1 & K10 & Personel Sayıs1 \\
\hline K2 & Ticari Uçak Sayısı & K11 & Kurtarma Cihaz Sayıs1 \\
\hline K3 & Yük Miktarı & $\mathbf{K 1 2}$ & $\begin{array}{l}\text { Hava Ve Radar Seyrüsefer } \\
\text { Sistemleri }\end{array}$ \\
\hline K4 & Yolcu Sayıs1 & $\mathbf{K 1 3}$ & Haberleşme Telsiz Cihazları \\
\hline K5 & Satış Gelirleri & $\mathbf{K 1 4}$ & En Yakın Merkeze Uzaklık \\
\hline K6 & Hizmet Giderleri & K15 & Denizden Yükseklik \\
\hline K7 & Yolcuya Hizmet Verilen Alan & $\mathbf{K 1 6}$ & Hava Sıcaklık Ortalaması \\
\hline K8 & $\begin{array}{l}\text { Yolcu Terminalleri Toplam } \\
\text { Alan }\end{array}$ & $\mathbf{K 1 7}$ & Yangınla Mücadele Kategorisi \\
\hline K9 & Bilgi İşlem Cihaz Sayısı & $\mathbf{K 1 8}$ & Araç Envanteri \\
\hline
\end{tabular}

Çalışmada ilk olarak karar matrisi oluşturulmuştur. Karar matrisi 20132018 yılları arasındaki verilerin ortalaması alınarak oluşturulmuştur. Havalimanlarının sadece bir veya son yıla ait verilerine bakarak değerlendirmenin sağlıklı olamayacağı düşünüldüğünden Tiryaki, Aydın ve Üçüncü, (2015: 938-949) ve Top, Yapıcı ve Çetinkaya'nın (2018: 107-119) çalışmalarında da olduğu gibi verilerin ortalaması alınmıştır. Oluşturulan karar matrisi Tablo 3.' teki gibidir. 


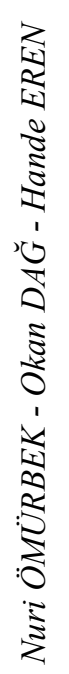

\begin{tabular}{|c|c|c|c|c|c|c|c|c|c|c|c|c|c|c|c|c|}
\hline & & 跔 & $\vdots$ &  & $\begin{array}{ll}\infty \\
0\end{array}$ & 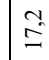 & $\stackrel{\stackrel{0}{=}}{\stackrel{2}{=}}$ & 6 & \pm & $\simeq$ & $\begin{array}{l}\tilde{I} \\
\Xi\end{array}$ & $\stackrel{\Xi}{\mathcal{I}}$ & $\stackrel{\infty}{=}$ & $\infty$ & $\begin{array}{l}\infty \\
\sim \\
\sim\end{array}$ & \\
\hline & & & & $a$ & & & $a$ & $\sigma$ & $\infty$ & & $\mid \begin{array}{c}0 \\
\infty \\
\infty\end{array}$ & $r$ & r & 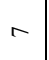 & r & . \\
\hline & & & & & & & n & & & & & $m$ & $\begin{array}{l}\text { तु } \\
\end{array}$ & & $\begin{array}{l}0 \\
f\end{array}$ & 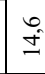 \\
\hline & & & $\begin{array}{c}n \\
\vdots \\
\vdots\end{array}$ & 4 & & & n. & & $\begin{array}{l}\infty \\
\vec{m}\end{array}$ & & $\mid \begin{array}{c}1 \\
\hat{2} \\
\hat{2}\end{array}$ & $\mid$\begin{tabular}{c}
1 \\
\multirow{f}{5}{} \\
0
\end{tabular} & $\left|\begin{array}{l}\tilde{y} \\
\dot{d} \\
0 \\
0\end{array}\right|$ & & $\mid \begin{array}{l}n \\
n \\
n\end{array}$ & \\
\hline & & ま & $\begin{array}{l}\tilde{a} \\
\tilde{a}\end{array}$ & & & $\frac{7}{7}$ & $\stackrel{+}{\circ}$ & & 曷 & & T & $\pi$ & \pm & $\exists$ & \begin{tabular}{|l|}
$\infty$ \\
$\curvearrowright$ \\
$\curvearrowright$
\end{tabular} & \\
\hline & & 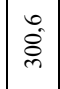 & & $\begin{array}{l}\mathcal{I} \\
J^{2}\end{array}$ & & స్ & $\stackrel{\infty}{\infty}$ & & $\overrightarrow{\tilde{z}}$ & & 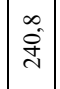 & 18 & $\because$ & สี & \begin{tabular}{|l|}
+ \\
$\infty$
\end{tabular} & \\
\hline & & & & & 잉 & & $\sigma^{2}$ & శુ & $\begin{array}{l}\infty \\
\infty \\
\infty\end{array}$ & $\infty$ & $\begin{array}{l}\dot{ } \\
\text { in }\end{array}$ & + & శூ & 4 & in & . \\
\hline & 8 & 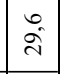 & 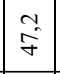 & 倳 & & તీ & $\stackrel{+}{\stackrel{i}{0}}$ & $\tilde{d}$ & $\vec{i}$ & & $\begin{array}{l}0 \\
\dot{d} \\
\end{array}$ & $\begin{array}{l}0 \\
\\
\end{array}$ & . & $\begin{array}{l}+ \\
\pm\end{array}$ & $\begin{array}{l}\tilde{I} \\
\mathcal{I}\end{array}$ & \\
\hline & & $\begin{array}{l}+ \\
\stackrel{d}{s}\end{array}$ & & os & & $\stackrel{0}{\circ}$ & $\begin{array}{l}n \\
\infty \\
\infty\end{array}$ & 6 & $\stackrel{\sim}{f}$ & & $\left|\begin{array}{l}0 \\
0 \\
\infty\end{array}\right|$ & $\begin{array}{c}0 \\
0 \\
\infty \\
\infty\end{array}$ & 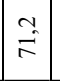 & $\begin{array}{l}\mathcal{O} \\
\mathcal{d}\end{array}$ & & \\
\hline & & i் & & 0 & \begin{tabular}{|l}
7 \\
0 \\
0 \\
0
\end{tabular} & & ह̂ & m & 0 & & 孛 & 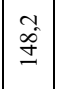 & $\approx$ & : & $\mid \begin{array}{l}0 \\
8\end{array}$ & \\
\hline & & : & 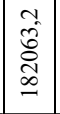 & $\begin{array}{l}\infty \\
\vdots \\
\vdots\end{array}$ & $m$ & S & $\overrightarrow{\vec{\sigma}}$ & 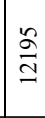 & 年 & nू & 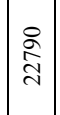 & 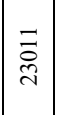 & 总 & $£$ & 守 & \\
\hline & & $\mid \begin{array}{l}0 \\
0 \\
0 \\
0 \\
\alpha \\
\sigma\end{array}$ & 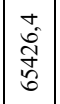 & 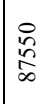 & & है & స్ర్రి & $\frac{n}{b}$ & $\begin{array}{l}2 \\
ٍ \\
=\end{array}$ & 品 & $\begin{array}{l}\text { 咅 } \\
\text { in }\end{array}$ & $\frac{1}{\tilde{\delta}}$ & 8 & $\mathscr{\circ}$ & & \\
\hline & & 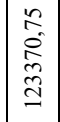 & $\mid \begin{array}{c}\vec{j} \\
\mathbb{i} \\
\mathbb{0} \\
\infty \\
-\end{array}$ & \begin{tabular}{|l} 
to. \\
त्रे
\end{tabular} & 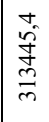 & 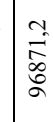 & $\begin{array}{l}\infty \\
\infty \\
0 \\
0 \\
0 \\
0 \\
0\end{array}$ & 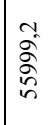 & 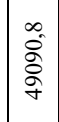 &  & 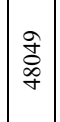 & $\mid \begin{array}{c}0 \\
\infty \\
\stackrel{\infty}{-}\end{array}$ & 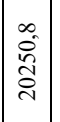 & $\begin{array}{l}\infty \\
\text { in }\end{array}$ & & \\
\hline & & 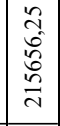 & $\begin{array}{c}+ \\
\tilde{D} \\
\hat{⿵} \\
\hat{i} \\
\end{array}$ & $\mid \begin{array}{l}7 \\
\text { ind } \\
0\end{array}$ & \begin{tabular}{l}
$\infty$ \\
\multirow{N}{*}{} \\
స̃ \\
$\infty$ \\
$\infty$
\end{tabular} & $\frac{1}{9}$ & ర్ల & $\begin{array}{l}\substack{0 \\
\infty} \\
\end{array}$ & 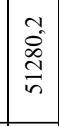 & 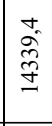 & $\mid$\begin{tabular}{c|c|} 
\\
$f$ \\
f \\
$m$
\end{tabular} & 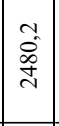 & $\begin{array}{l}0 \\
2 \\
2\end{array}$ & 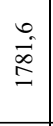 & & \\
\hline & & 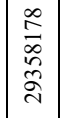 & 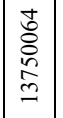 & $\begin{array}{l}0 \\
\text { g్ }\end{array}$ & $f$ & $\frac{8}{y}$ & $\begin{array}{l}\infty \\
\text { D } \\
\text { d } \\
\text { d }\end{array}$ & to & $\infty$ & $\begin{array}{l}\infty \\
\infty \\
\infty \\
ٍ\end{array}$ & 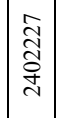 & 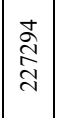 & $\left|\begin{array}{l}n \\
\vdots \\
\hat{\sigma} \\
i\end{array}\right|$ & & & \\
\hline & & 总 & 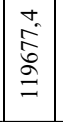 & de & $\begin{array}{l}0 \\
0 \\
00^{\circ} \\
0 \\
0\end{array}$ & $\begin{array}{l}\text { 离 } \\
\stackrel{8}{\sigma}\end{array}$ & & $\begin{array}{c}\text { 旁 } \\
+\end{array}$ & $\begin{array}{c}m \\
\hat{m} \\
\tilde{m}\end{array}$ & ర్ & 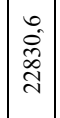 & $\mid \begin{array}{l}0 \\
0 \\
\infty \\
\infty \\
-\end{array}$ & : & & & \\
\hline & & \begin{tabular}{l}
0 \\
\multirow{0}{0}{} \\
$\stackrel{0}{0}$
\end{tabular} & 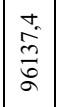 & & $\bar{a}$ & 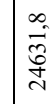 & 告 & 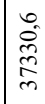 & d & 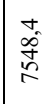 & 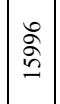 & $\begin{array}{c}0 \\
0 \\
0\end{array}$ & $\mid \begin{array}{l}\infty \\
0 \\
0 \\
0 \\
0\end{array}$ & & & \\
\hline 5 & & 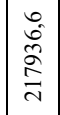 & 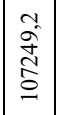 & & & 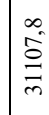 & $\begin{array}{l}t \\
0 \\
\tilde{N} \\
\tilde{N}\end{array}$ & & $\begin{array}{l}\infty \\
\text { i } \\
\text { ì } \\
\text { an }\end{array}$ & $\infty$ & 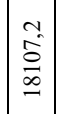 &  & 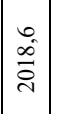 & & 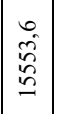 & \\
\hline 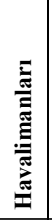 & & 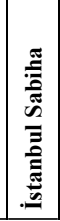 & 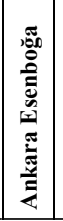 & & 1 & 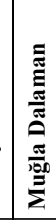 & $\stackrel{0}{0}$ & & 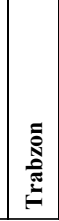 & & 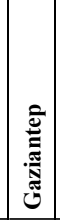 & 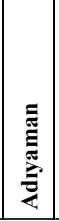 & 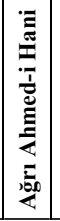 & & 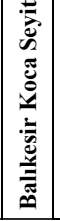 & \\
\hline
\end{tabular}




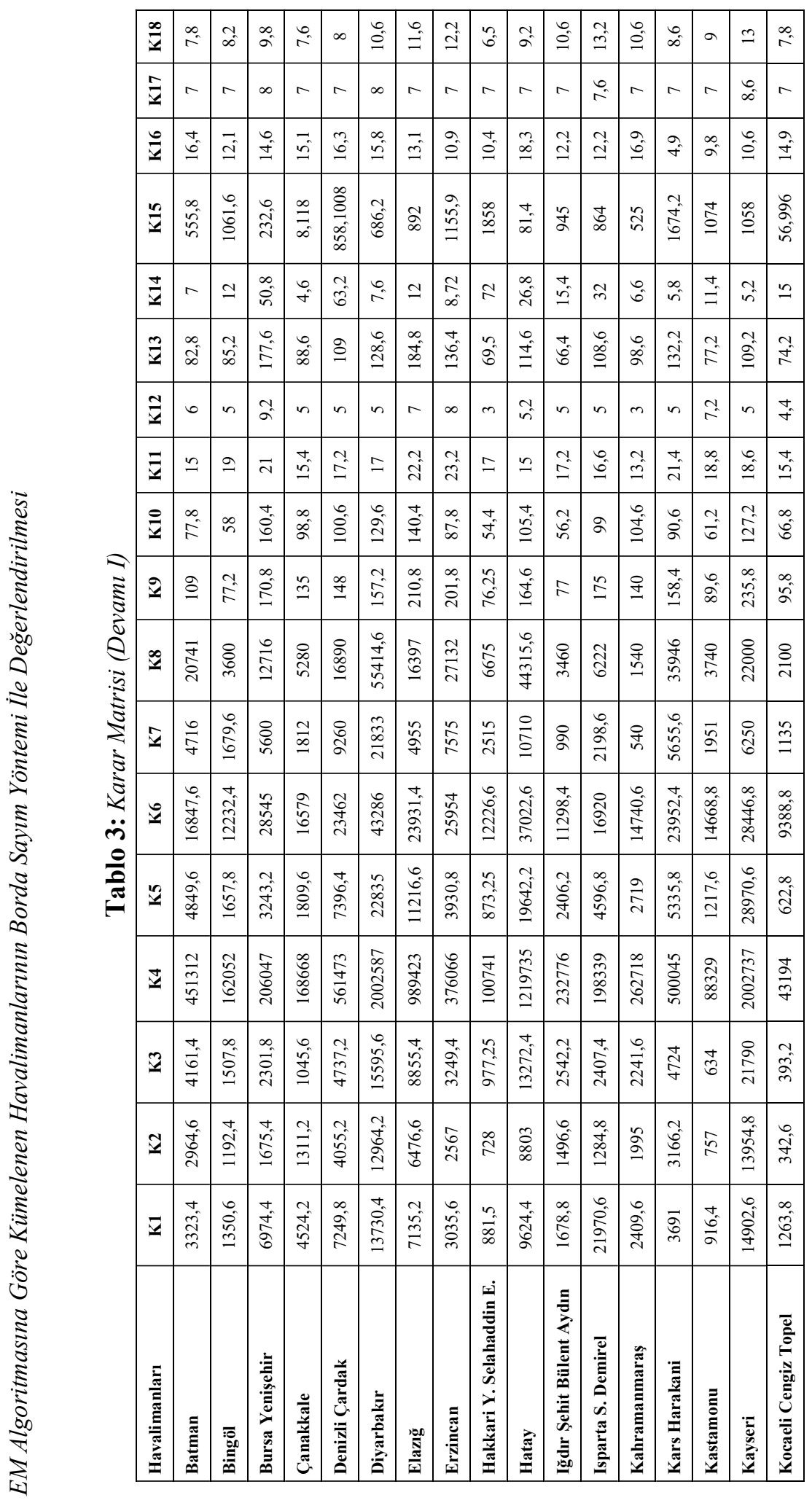

ڤิ) 
至

\begin{tabular}{|c|c|c|c|c|c|c|c|c|c|c|c|c|c|c|c|c|}
\hline $\bar{\Xi}$ & $\stackrel{\overbrace{}}{\varrho}$ & $\begin{array}{l}\infty \\
\sigma_{0}\end{array}$ & 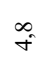 & $\begin{array}{l}\infty \\
\infty \\
\infty\end{array}$ & $\therefore$ & $\cong$ & $\begin{array}{l}0 \\
\infty \\
\infty\end{array}$ & $\therefore$ & $\cong$ & İ & $\underbrace{\infty}_{0}$ & $\begin{array}{l}0 \\
i \\
\text { in }\end{array}$ & $\begin{array}{l}\mathcal{I} \\
\mathcal{I}\end{array}$ & $\infty$ & ठु & $\stackrel{\forall}{\sigma}$ \\
\hline $\bar{\Xi}$ & $\infty$ & $\infty$ & $r$ & r & r & $1-$ & $\infty$ & Sु & $b_{0}^{0}$ & $\infty$ & $a$ & $r$ & $\stackrel{\infty}{\sim}$ & तु & ठु & $\infty$ \\
\hline$\stackrel{0}{\Xi}$ & $\stackrel{0}{=}$ & $\stackrel{0}{\simeq}$ & $\vec{\sigma}$ & $\vec{\sigma}$ & $\hat{\varrho}$ & 吕 & $\stackrel{n}{ \pm}$ & $\overrightarrow{\underline{G}}$ & I & $a$ & $\underline{\underline{\infty}^{2}}$ & $\overrightarrow{5}$ & \pm & $\begin{array}{l}\text { I } \\
\stackrel{I}{i}\end{array}$ & 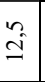 & 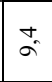 \\
\hline$\stackrel{n}{\underline{z}}$ & $\begin{array}{l}\infty \\
\stackrel{\infty}{0} \\
\stackrel{0}{3}\end{array}$ & 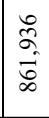 &  & 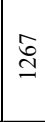 & 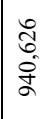 & $\mathrm{m}$ & $\begin{array}{c}\tilde{\sigma} \\
\text { s. }\end{array}$ & $\frac{8}{6}$ & त्तू & $\begin{array}{l}0 \\
0 \\
\alpha \\
\alpha \\
\omega \\
\omega\end{array}$ & $\underset{\infty}{2}$ & 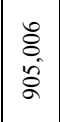 & 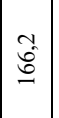 & $\begin{array}{l}\hat{0} \\
b^{\circ} \\
n^{2}\end{array}$ & 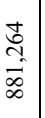 & 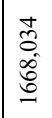 \\
\hline$\vec{\Xi}$ & $\stackrel{\infty}{\infty}$ & $\frac{y}{m}$ & $\stackrel{+}{ \pm}$ & $\stackrel{\infty}{=}$ & i & I & $\begin{array}{l}\infty \\
\stackrel{+}{+}\end{array}$ & \pm & $\cong$ & 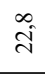 & $\begin{array}{l}\text { f } \\
\text { f }\end{array}$ & $\begin{array}{l}2 \\
\delta \\
\delta\end{array}$ & aे & $\begin{array}{l}\circ \\
\stackrel{0}{2}\end{array}$ & $r$ & $\stackrel{\infty}{\sim}$ \\
\hline$\underline{\underline{a}}$ & $\begin{array}{l}+ \\
\text { s. } \\
\text { ñ. }\end{array}$ & $\begin{array}{l}\infty \\
\infty \\
\infty\end{array}$ & ळo & 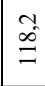 & $\cong$ & 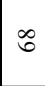 & $\begin{array}{l}\underset{+}{+} \\
\stackrel{+}{ \pm}\end{array}$ & $\begin{array}{l}\infty \\
b^{2}\end{array}$ & $\stackrel{\infty}{\stackrel{\infty}{a}}$ & 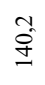 & $\cong$ & $\approx$ & 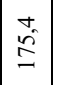 & $\begin{array}{l}0 \\
\dot{\infty}\end{array}$ & $\begin{array}{l}\infty \\
\sigma^{\infty}\end{array}$ & $\begin{array}{l}0 \\
0 \\
0\end{array}$ \\
\hline$\tilde{\Xi}$ & $\infty$ & in & $\stackrel{\mathcal{F}}{f}$ & in & in & $\begin{array}{l}\therefore \\
\therefore\end{array}$ & in & t & $\stackrel{f}{f}$ & $r$ & 0 & in & $\begin{array}{l}0 \\
i\end{array}$ & $m$ & $m$ & in \\
\hline $\bar{z}$ & 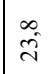 & $\stackrel{\infty}{\infty}$ & $=$ & a & - & $=$ & ì & - & $\begin{array}{l}0 \\
\stackrel{0}{2}\end{array}$ & $\begin{array}{l}\text { ते } \\
\text { ẑ }\end{array}$ & ְై & $\begin{array}{l}\infty \\
=\end{array}$ & I & & $\stackrel{\circ}{\overbrace{\infty}^{\circ}}$ & 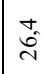 \\
\hline
\end{tabular}

:

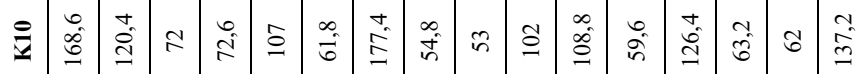

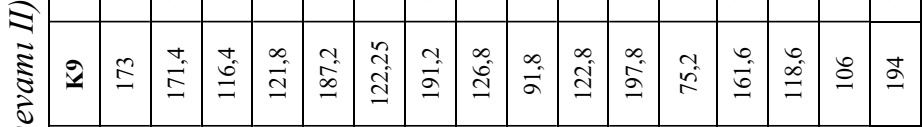



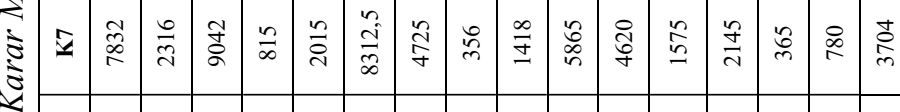

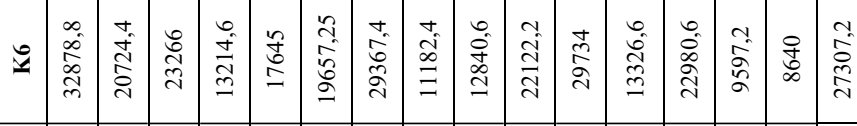

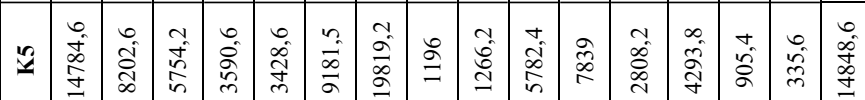



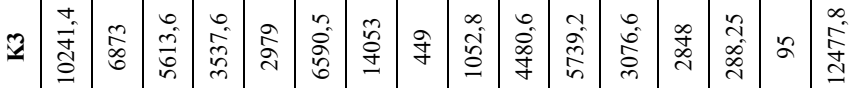

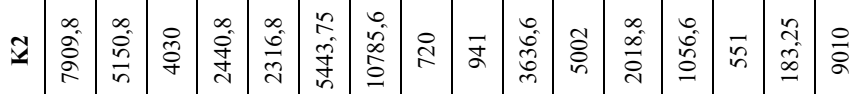

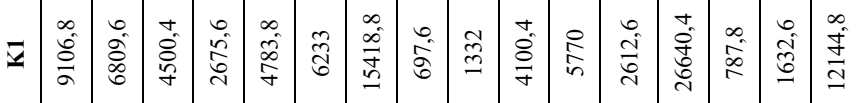

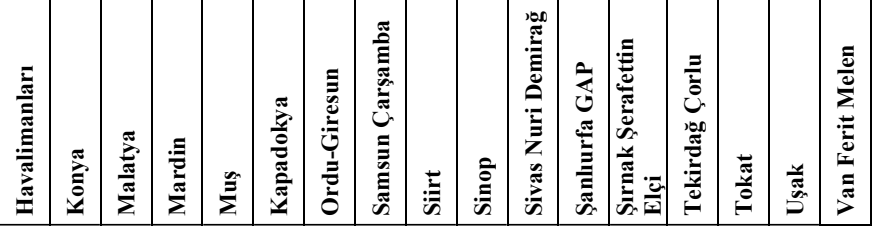

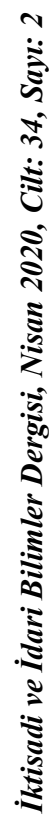


EM Algoritmasına Göre Kümelenen Havalimanlarının Borda Sayım Yöntemi İle Değerlendirilmesi

Yapılan literatür incelemesi sonucunda kümeleme analizlerinde genellikle verilerin WEKA programına yüklenerek kümeleme analizinin yapıldığı görülmüştür. Ancak bu çalışmada havaalimanlarının kümelenmesinde kullanılan kriterlerin eşit önem seviyesine sahip olmadığı düşünülmektedir. Bundan dolay1 ilk önce ENTROPI yöntemi ile kriter ağırlıkları hesaplanarak karar matrisindeki verilerle çarpılıp daha sonra WEKA programına yüklenmiştir.

4.1.ENTROPI Yöntemi İle Kriter Ağırlıklarının Hesaplanması

$\mathrm{Bu}$ bölümde Entropi yöntemi aşamaları uygulanarak kriter ağırlıklarının yer aldı ̆̆ı Tablo 4. aşağıda verilmiştir.

Adım 1: Karar Matrisinin Oluşturulması: Çalışmada kriter ağırlıklarının hesaplanmasında Entropi yöntemi kullanılmıştır. DHMİ' den alınan 2013-2018 yıllarına ait verilerin ortalaması alınarak karar matrisi (Tablo 3.) elde edilmiştir.

Adım 2: Fayda ve Maliyet Kriterine Göre Normalizasyon Matrisinin Oluşturulmasl: Karar matrisinin fayda ve maliyet kriterine göre normalizasyon işlemi için ilk olarak Eşitlik 1 ve Eşitlik 2' den yararlanılmıştır. Daha sonra her bir ilgili kriter değerinin toplamına ilgili alternatifin kriter değeri bölünerek normalizasyon işlemi yapılmıştır.

Adım 3: K Değerinin ve ENTROPI $\left(E_{j}\right)$ Değerinin Hesaplanması: $\mathrm{Bu}$ adımda bir önceki adımda elde edilen matristeki her bir kriter değerinin logaritma değeri alınmıştır. Bu logaritma değerleri ile kriter değerleri çarpılarak bir matris elde edilmiştir.

$\mathrm{K}=1 /$ ln.n sabit bir sayı olmak üzere $0 \leq \mathrm{e}_{\mathrm{j}} \leq 1$ olmasını sağlamaktadır. Çalışmada $\mathrm{n}=49$ olduğu için $\mathrm{K}=1 / \ln 49=0,25694917$ olarak hesaplanmıştır.

$\mathrm{K}$ değerinin hesaplanmasının ardından bir önceki matristeki her bir kriterin sütun toplamı ile $\mathrm{K}$ değeri Eşitlik 4' te gösterildiği gibi çarpılarak $\mathrm{E}_{\mathrm{j}}$ değeri hesaplanmıştır.

Adım 4: $d_{j}$ Değerinin Hesaplanması: $\mathrm{E}_{\mathrm{j}}$ değeri hesaplandıktan sonra $\mathrm{d}_{\mathrm{j}}$ değerleri Eşitlik 5 yardımıyla hesaplanmıştır. Yani her bir $E_{j}$ değerinden 1 çıkartılarak $\mathrm{d}_{\mathrm{j}}$ değerine ulaşı1mıştır.

Adım 5: Kriter Ăgırlıklarının Hesaplanması: Adım 5'te kriter ağırlıkları hesaplanmıştır. Her bir $\mathrm{d}_{\mathrm{j}}$ değeri toplam $\mathrm{d}_{\mathrm{j}}$ değerine bölünerek kriter ağırlıkları hesaplanmıştır.

Tablo 4: ENTROPI Kriter A ğırlık Değerleri

\begin{tabular}{|c|c|c|c|c|c|c|c|c|c|c|}
\hline & K1 & K2 & K3 & K4 & K5 & K6 & K7 & K8 & K9 & \multirow{2}{*}{} \\
\cline { 1 - 10 } $\mathbf{W}_{\mathbf{j}}$ & 0,0948 & 0,1092 & 0,1565 & 0,1082 & 0,1427 & 0,0174 & 0,0716 & 0,0697 & 0,0213 & \\
\hline & $\mathbf{K 1 0}$ & $\mathbf{K 1 1}$ & $\mathbf{K 1 2}$ & $\mathbf{K 1 3}$ & $\mathbf{K 1 4}$ & $\mathbf{K 1 5}$ & $\mathbf{K 1 6}$ & $\mathbf{K 1 7}$ & $\mathbf{K 1 8}$ & Toplam \\
\hline $\mathbf{W}_{\mathbf{j}}$ & 0,0298 & 0,0055 & 0,0132 & 0,0284 & 0,0161 & 0,0996 & 0,0021 & 0,0006 & 0,0133 & 1 \\
\hline
\end{tabular}

Entropi yöntemi ile elde edilen ağırlıklar dikkate alındığında en fazla öneme sahip olan kriter yük miktarı (K3) ile satış gelirleri (K5) kriterleridir. En az öneme sahip olan kriter ise yangınla mücadele kategorisi (K18) kriteri olmuştur. 


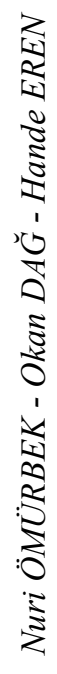

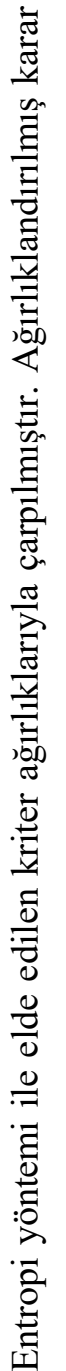

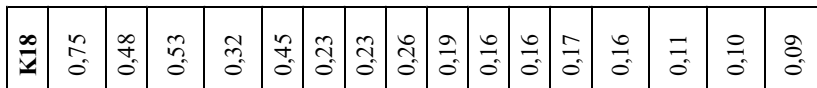

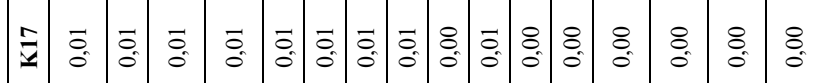

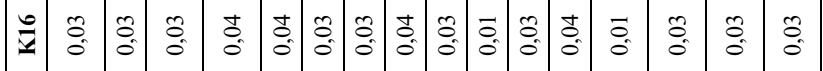

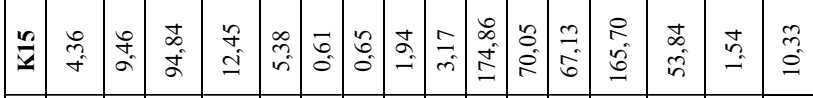

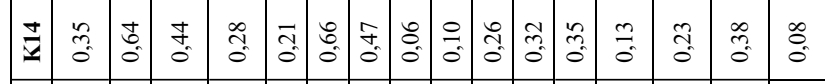

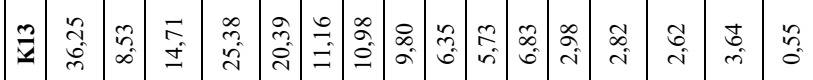

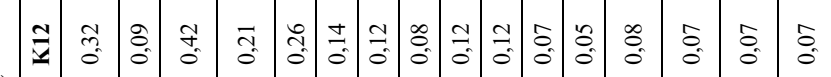

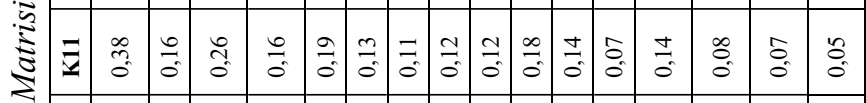

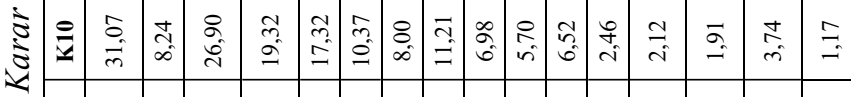



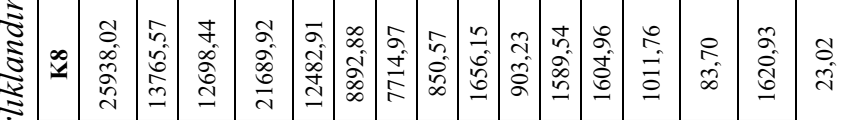

$\stackrel{\circ}{10}$

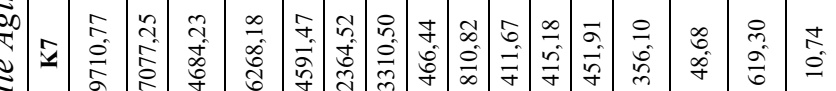

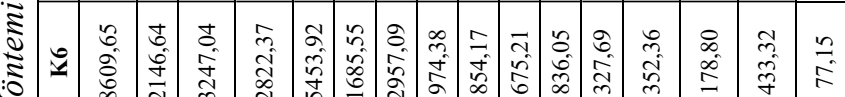

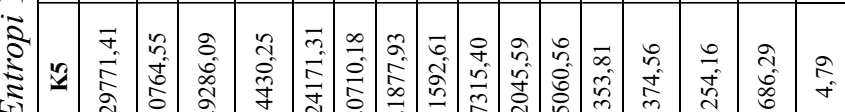

可



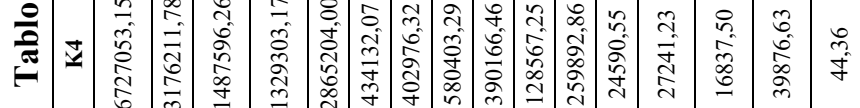

章:

S.

इ तี



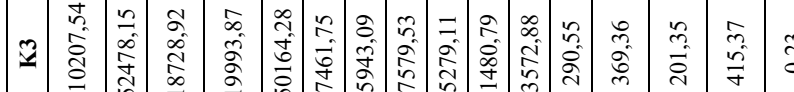

莡

₹ $\frac{0}{0}$

$\cong$.

政

:

记节



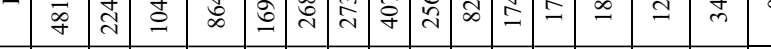

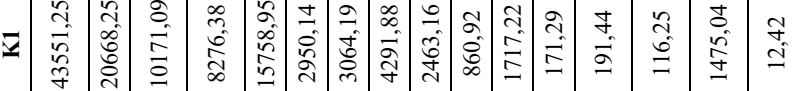

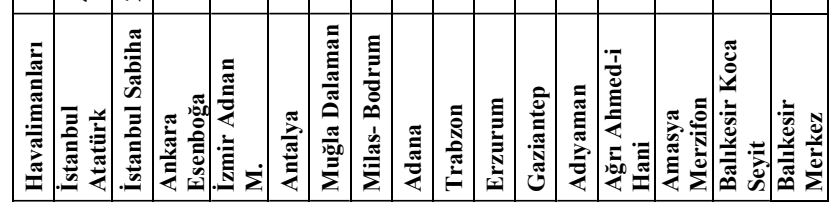

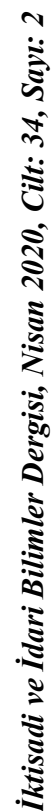




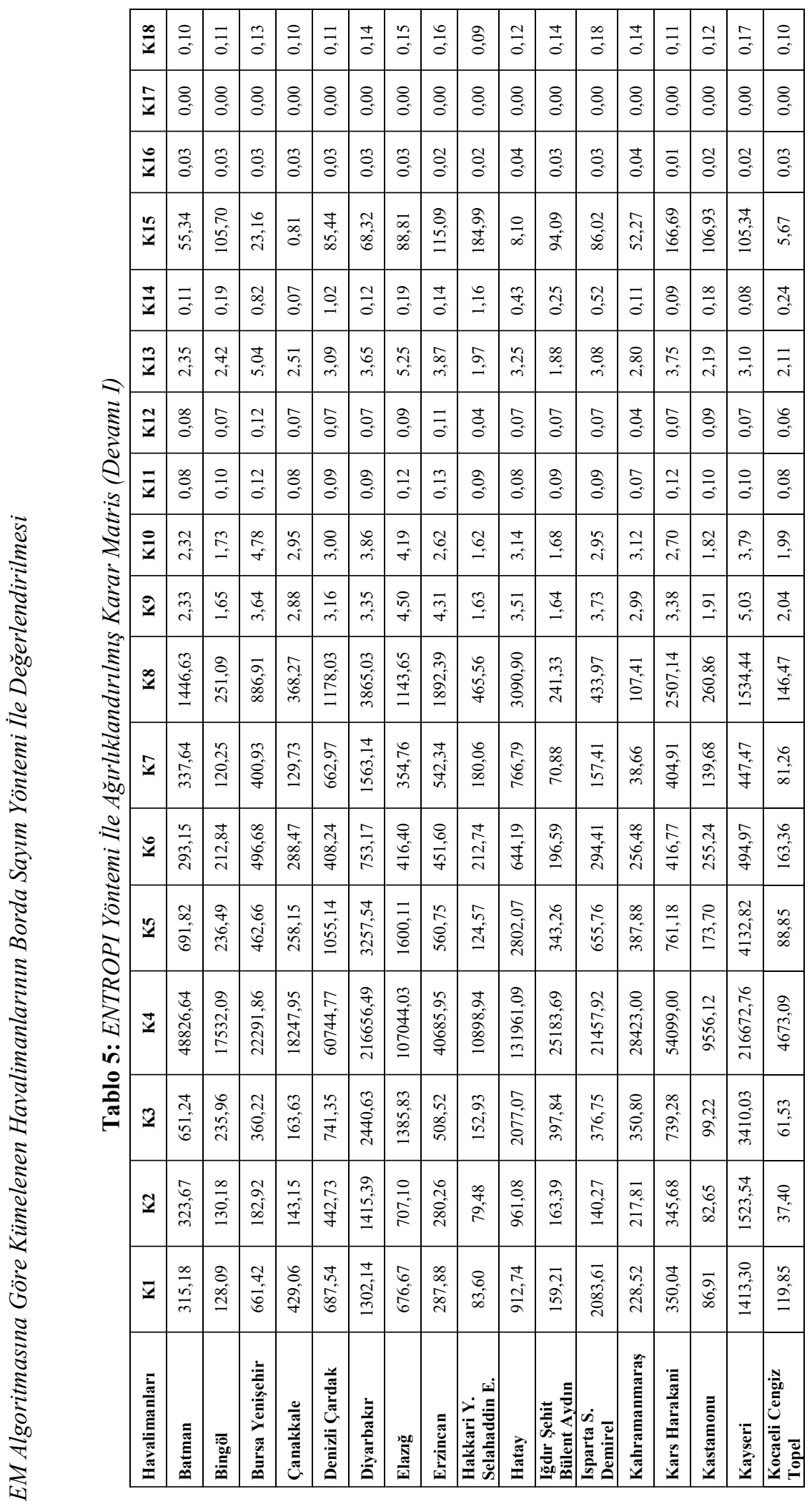




齐

\begin{tabular}{|c|c|c|c|c|c|c|c|c|c|c|c|c|c|c|c|c|c|}
\hline$\stackrel{\infty}{\underline{\underline{Z}}}$ & $\stackrel{ \pm}{0}$ & $\stackrel{m}{0}$ & $\stackrel{\circ}{\circ}$ & $\cong$ & $\stackrel{m}{0}$ & $\div$ & $=$ & $\stackrel{\circ}{\circ}$ & 0 & $\stackrel{5}{0}$ & : & s. & $\stackrel{2}{0}$ & 0 & $\begin{array}{l}\infty \\
0 \\
0\end{array}$ & $\stackrel{m}{0}$ & $\begin{array}{l}n \\
0 \\
0\end{array}$ \\
\hline$\overline{\underline{y}}$ & $\begin{array}{l}8 \\
0\end{array}$ & $\begin{array}{l}8 \\
0\end{array}$ & $\because$ & 8 & 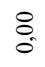 & $\stackrel{8}{\circ}$ &  & $\begin{array}{l}8 \\
0 \\
0\end{array}$ & & $\therefore$ & $\bar{D}_{0}$ & 8 & $\stackrel{8}{\circ}$ & & $:$ & $\begin{array}{l}8 \\
0\end{array}$ & $\bar{\sigma}_{0}$ \\
\hline$\stackrel{\circ}{\Xi}$ & $\begin{array}{l}\tilde{c} \\
\tilde{0}\end{array}$ & $\begin{array}{l}0 \\
0 \\
0\end{array}$ & $\stackrel{8}{0}$ & $\therefore$ & $\tilde{\delta}$ & $\stackrel{0}{0}$ & $\stackrel{0}{0}$ & $\stackrel{8}{0}$ & 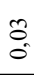 & $\tilde{\delta}$ & 咅 & $\stackrel{8}{8}$ & $\stackrel{8}{8}$ & : & $\stackrel{0}{0}$ & $\begin{array}{l}\tilde{O} \\
\stackrel{0}{0}\end{array}$ & $\stackrel{8}{0}$ \\
\hline$\frac{10}{\square}$ & $\begin{array}{l}\tilde{\hat{~}} \\
\underline{\tilde{\delta}}\end{array}$ & $\begin{array}{l}0 \\
\infty \\
\infty \\
\infty\end{array}$ & $\begin{array}{l}\text { o } \\
\text { î } \\
\text { in }\end{array}$ & $\begin{array}{l}\stackrel{n}{0} \\
\stackrel{5}{0}\end{array}$ & $\begin{array}{l}\tilde{b} \\
\kappa^{2}\end{array}$ & $\tilde{c}_{0}^{0}$ & $\begin{array}{l}n \\
\hat{0} \\
0\end{array}$ & $\begin{array}{l}\hat{0} \\
\hat{8}\end{array}$ & مू & 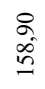 & 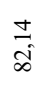 & $\begin{array}{l}= \\
\text { s. }\end{array}$ & $\begin{array}{l}n \\
\text { ñ. } \\
\text { - }\end{array}$ & 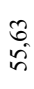 & 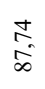 & $\begin{array}{l}\infty \\
0 \\
\mathbb{0}^{-1}\end{array}$ & 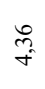 \\
\hline$\Xi$ & ते & $\begin{array}{l}0 \\
n \\
0\end{array}$ & ก. & ते & $\begin{array}{l}\infty \\
0 \\
0\end{array}$ & हे & I & तु & 0 & ?. & $\begin{array}{l}n \\
n \\
0\end{array}$ & go & fó & 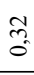 & $=$ & $\stackrel{m}{0}$ & $\tilde{m}_{0}^{2}$ \\
\hline$\underline{\underline{z}}$ & $\begin{array}{l}\hat{N} \\
f\end{array}$ & $\begin{array}{l}0 \\
i \\
i\end{array}$ & $\begin{array}{l}n \\
i \\
i\end{array}$ & $\stackrel{m}{m}$ & $\begin{array}{l}\vec{m} \\
\dot{f}\end{array}$ & $\stackrel{\Omega}{-}$ & $\begin{array}{l}\underset{2}{2} \\
\text { in }\end{array}$ & $\stackrel{\substack{\infty \\
\rightarrow}}{-}$ & - & $\stackrel{\infty}{\stackrel{m}{m}}$ & $\begin{array}{l}\vec{m} \\
\vec{f}\end{array}$ & $\underset{\stackrel{\Phi}{+}}{-}$ & $\begin{array}{l}\infty \\
\stackrel{\infty}{+}\end{array}$ & i & $\begin{array}{l}\approx 0 \\
i \\
i\end{array}$ & $\begin{array}{l}\stackrel{2}{2} \\
\stackrel{2}{2}\end{array}$ & $\begin{array}{l}\text { ते } \\
\text { - }\end{array}$ \\
\hline$\Xi$ & $\begin{array}{l}= \\
0\end{array}$ & $\begin{array}{l}0 \\
0 \\
0\end{array}$ & $\stackrel{\circ}{\circ}$ & $\begin{array}{l}5 \\
0 \\
0\end{array}$ & : & : & i. & $\begin{array}{l}8 \\
0 \\
0\end{array}$ & & $\stackrel{g}{0}$ & $\stackrel{\infty}{0}$ & $\delta_{0}$ & $\delta_{0}$ & & to & $\begin{array}{l}0 \\
0 \\
0\end{array}$ & $\stackrel{3}{0}$ \\
\hline 1 & $\begin{array}{l}m \\
0\end{array}$ & $\stackrel{0}{0}$ & 0 & $\overrightarrow{0}$ & $\overrightarrow{0}$ & 8 & 5 & 0 & & $0^{\circ}$ & $\overrightarrow{0}$ & $\overrightarrow{0}$ & $\overrightarrow{0}$ & & $0^{\circ}$ & $\frac{n}{0}$ & $\begin{array}{c}\infty \\
\vdots \\
0\end{array}$ \\
\hline
\end{tabular}





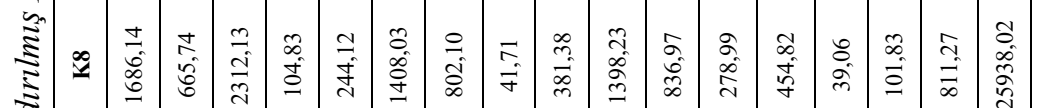

is

|

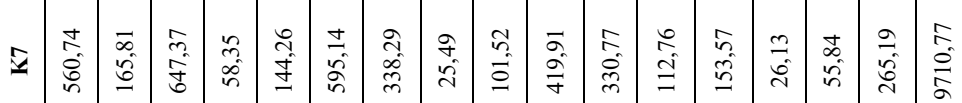

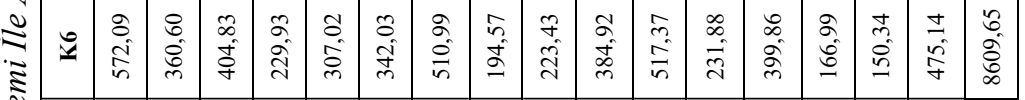

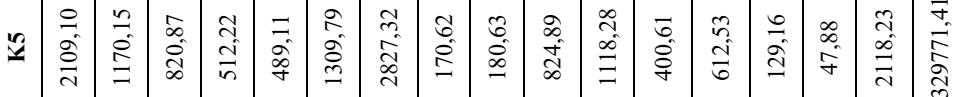

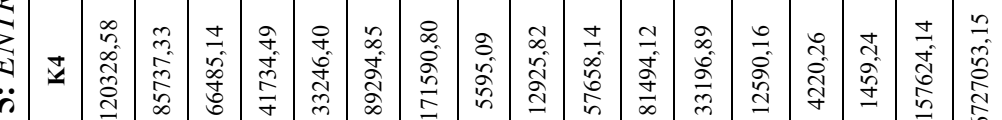

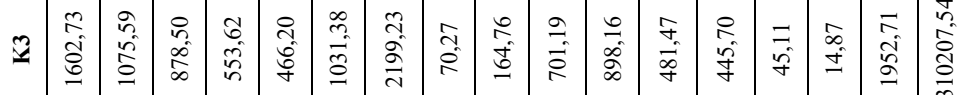

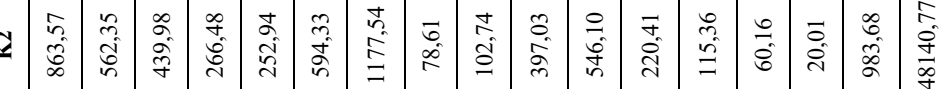

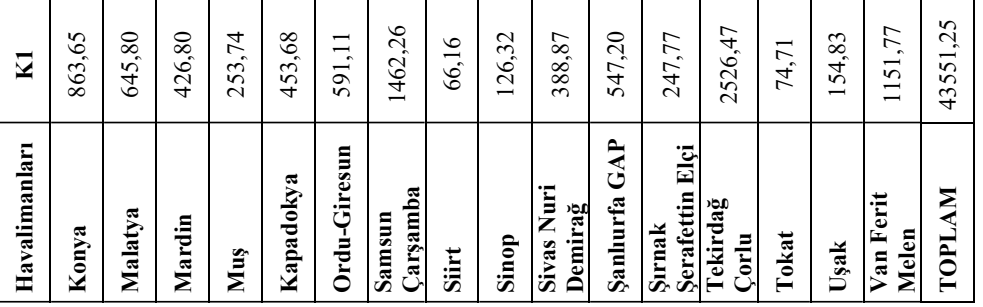

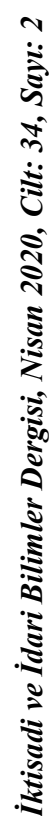


EM Algoritmasına Göre Kümelenen Havalimanlarının Borda Sayım Yöntemi İle Değerlendirilmesi

Tablo 5.'teki değerler WEKA programına yüklenerek en uygun algoritmanın seçilmesi amaçlanmıştır. Yapılan analizde farklı algoritmaların denenmesi sonucunda en tutarlı sonuçları EM algoritmasının verdiği görülmüştür.

Küme sayısının belirlenmesi için genellikle $\mathrm{k}=(\mathrm{n} / 2)^{1 / 2}$ eşitliğinden yararlanılmaktadır (Turanlı vd., 2006: 100). Bu çalışmada da yapılan hesaplamalara göre küme sayısı 5 olarak belirlenmiştir.

Verilerin WEKA programına yüklenmesi ile Şekil 1'deki temel analizler gerçekleştirilmiştir.

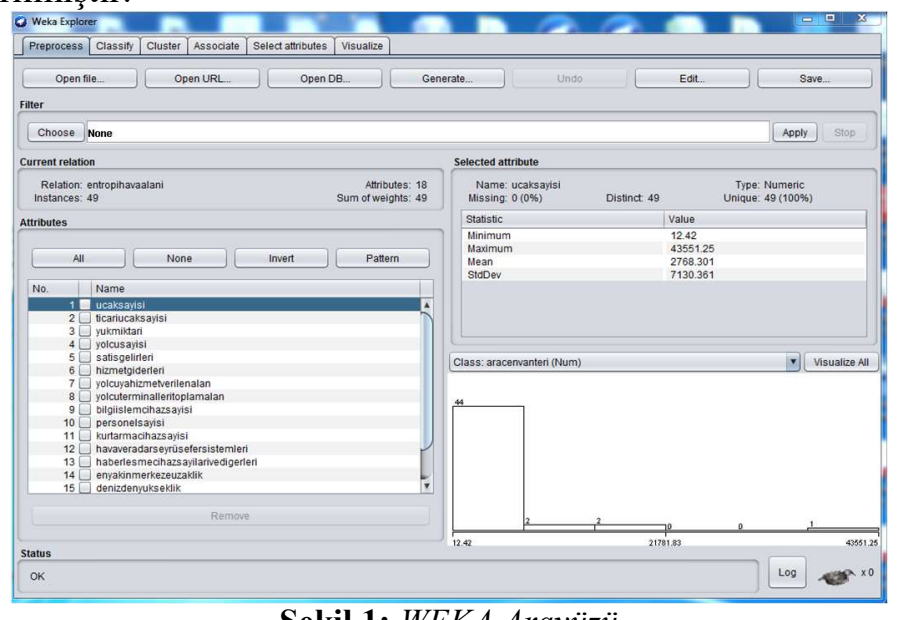

Şekil 1: WEKA Arayüzü

Şekil 1.' de gösterilen ekranda yer alan 'Current Relation” başlığı altında yüklenen verinin ismi, kaç tane örneğe ve özniteliğe sahip olduğu görülmektedir. Verilerden sol tarafta seçili olan öznitelikle alakalı olarak minimum, maksimum, standart sapma ve ortalama değer bilgileri ekranın sağ tarafında yer alan "Selected Attribute" başlı̆̆ı altında yer almaktadır. Seçilen kritere ait dağılım ise sağ alt köşede bulunan grafikte yer almaktadır.

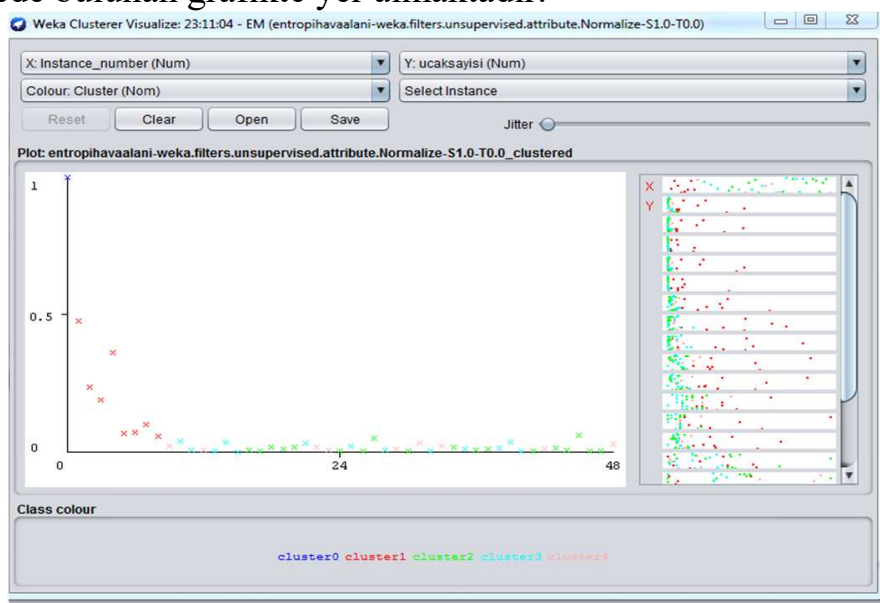

Şekil 2: WEKA Sonuç Paneli 
Şekil 2.'de yer alan sonuç paneline bakıldığında Cluster 1' de yer alan havalimanlarının birbirlerine olan mesafelerinin daha fazla olduğu görülmektedir. Diğer kümelerde yer alan havalimanlarının birbirilerine olan mesafeleri ise daha yakındır.

WEKA programı ile yukarıda açıklanan adımlar takip edilerek yapılan kümeleme analizi sonucunda elde edilen kümeler Tablo 6.' da görülmektedir.

Tablo 6. Havalimanlarının Kümeleme Sonuçları

\begin{tabular}{|c|c|c|c|c|}
\hline CLUSTER 0 & CLUSTER 1 & CLUSTER 2 & CLUSTER 3 & CLUSTER 4 \\
\hline \multirow[t]{18}{*}{ İstanbul Atatürk } & İstanbul Sabiha & Batman & Gaziantep & Erzurum \\
\hline & Ankara Esenboğa & Bingöl & Adiyaman & Ağrı Ahmed-i Hani \\
\hline & İzmir Adnan M. & Bursa Yenişehir & Amasya Merzifon & Elazığ \\
\hline & Antalya & Çanakkale & Balıkesir Koca Seyit & Erzincan \\
\hline & Muğla Dalaman & Denizli Çardak & Balıkesir Merkez & Kars Harakani \\
\hline & Milas- Bodrum & $\begin{array}{l}\text { Hakkari Y. } \\
\text { Selahaddin E. }\end{array}$ & Diyarbakır & Kayseri \\
\hline & Adana & $\begin{array}{l}\text { Iğdır Şehit Bülent } \\
\text { Aydın }\end{array}$ & Hatay & Konya \\
\hline & Trabzon & Isparta S. Demirel & Kahramanmaraş & Sivas Nuri Demirağ \\
\hline & & Kastamonu & $\begin{array}{l}\text { Kocaeli Cengiz } \\
\text { Topel }\end{array}$ & Van Ferit Melen \\
\hline & & Malatya & Mardin & \\
\hline & & Muş & Ordu-Giresun & \\
\hline & & Kapadokya & Samsun Çarşamba & \\
\hline & & Sinop & Siirt & \\
\hline & & Şanlıurfa GAP & & \\
\hline & & $\begin{array}{l}\text { Şırnak Şerafettin } \\
\text { Elçi }\end{array}$ & & \\
\hline & & Tekirdağ Çorlu & & \\
\hline & & Tokat & & \\
\hline & & Uşak & & \\
\hline
\end{tabular}

\subsection{BORDA Yönteminin Uygulanmast}

Çalışmada kümeleme analizi sonucunda elde edilen kümelerin BORDA Sayım Yöntemine göre performansları açısından sıralanması da amaçlanmıştır. Bu amaçla her bir kümede yer alan havalimanlarının her bir kriter açısından almış oldukları değerlerin ortalamasına göre Tablo 7 oluşturulmuş ve bu değerlere göre BORDA skorları verilerek BORDA Sayım Yöntemine göre nihai sıralama elde edilmiştir. 

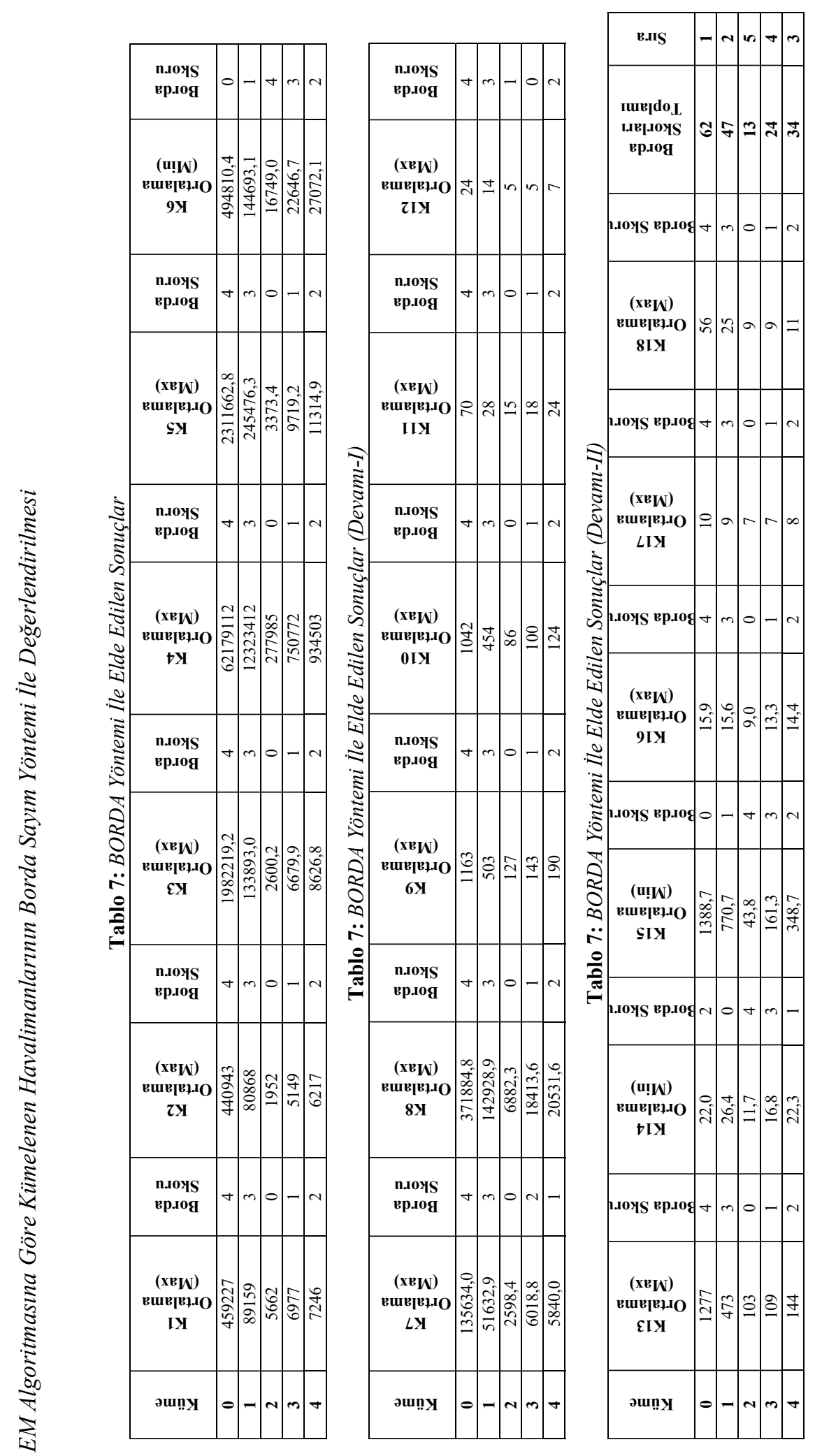

ญे. 
BORDA yönteminin uygulanması sırasında en son sırada yer alan kümeye 0 puanı verilirken; ilk sıradaki kümeye 4 puan verilmiştir. Verilen puanlar sonucunda en yüksek BORDA skoruna sahip olan küme en iyi performansı gösteren küme olarak belirlenmiştir. Cluster 0 mevcut 18 kriterden 15 tanesinde en iyi puanı alarak toplamda 62 puanla ilk sırada yer almıştır. En son sırada bulunan Cluster 2 ise 18 kriterden 14' ünde en düşük puanı alarak toplamda 13 puan ile son sırada yer almıştır.

\section{Sonuç ve Değerlendirme}

$\mathrm{Bu}$ çalışmada 49 havalimanı WEKA programında EM algoritması uygulanarak kümeleme analizi yapılarak kümelere ayrılmıştır. Analiz sonucunda 5 küme meydana gelmiştir. Oluşturulan kümeler BORDA Sayım yöntemiyle puanlanmıştır.

Çalışmada Türkiye' de yer alan 55 havalimanından eksiksiz veriye sahip 49 havalimanına yer verilmiştir. Tablo 8.' de yer alan havalimanlarının kümeleme sonuçlarına bakıldığında Cluster 0' daki İstanbul Atatürk Havalimanı uçak sayısı, ticari uçak sayısı, yolcu sayısı, satı̧̧ gelirleri, yolcuya hizmet verilen alan, yolcu terminalleri toplam alan, bilgi işlem cihaz sayısı, personel sayısı, kurtarma cihaz sayısı, hava ve radar seyrüsefer sistemleri, haberleşme ve telsiz cihazları, en yakın merkeze uzaklık, denizden yükseklik ve araç envanteri kriterleri açısından diğer kümelerden ayrılmaktadır. Cluster 1'deki havalimanlarının tamamı büyükşehirlerde yer alan havalimanlarını kapsamaktadır. Cluster 3 ve Cluster 4' te yer alan havalimanları Cluster 0 ve Cluster 1' e göre fazla aktif olmayan havalimanlarıdır. Son olarak Cluster 2' deki havalimanları ise hizmet giderleri, hava ve seyrüsefer sistemleri, en yakın merkeze uzaklık ve denizden yükseklik kriterleri bakımından üst sıralarda yer alsa da diğer kriterlere bakıldığında alt siralarda olduğu görülmektedir. $\mathrm{Bu}$ yüzden Cluster 2 en az aktif küme konumundadır. Bu sonuçlara bakıldığında çalışmanın kısmen güvenilirliğini test etmek ve kümelerin performanslarını değerlendirmek amacıyla BORDA Sayım yöntemi uygulanmıştır. BORDA Sayım yönteminden elde edilen sonuçlara bakıldığında "Cluster 0" toplam 62 skorla ilk sirada yer alırken; "Cluster 1" toplam 47 skorla ikinci, "Cluster 4" toplam 34 skorla üçüncü, "Cluster 3" toplam 24 skorla dördüncü ve son olarak "Cluster 2" toplam 13 puanla beşinci sırada yer almıştır. BORDA Sayım yönteminin sonuçları, WEKA programı ile yapılan Kümeleme analizinin sonuçlarıyla karşılaştırıldığında elde edilen sonuçların tutarl111k gösterdiği görülmüştür.

\section{Kaynaklar}

Adikariwattage, V., Barros, A.G., Wirasinghe S.C. ve Ruwanpura J. (2012), Airport Classification Criteria Based On Passenger Characteristics and Terminal Size. Journal of Air Transport Management, 24, 36-41. Retrieved from https://www.sciencedirect.com/science/article/abs/pii/ S0969699712000944

Alptekin, N. ve Yeşilaydın, G. (2015), OECD Ülkelerinin Sağlık Göstergelerine Göre Bulanık Kümeleme Analizi İle Sinıflandırılması. Journal Of Business 
EM Algoritmasına Göre Kümelenen Havalimanlarının Borda Sayım Yöntemi İle Değerlendirilmesi

Research Turk, 7(4), 137-155. Retrieved from https://www.isarder.org/2015/vol.7_issue.4_article07_full_text.pdf

Alzand, H. R. A. ve Karacan, H. (2014), Bölümleyici Küme-leme Algoritmalarının Farklı Veri Yoğunluklarında Karşılaştırılması. Erciyes Üniversitesi Fen Bilimleri Enstitüsü Dergisi, 30(1), 56-62. Retrieved from https://dergipark.org.tr/en/download/article-file/236098

Anderberg, M. R. (1973), Cluster Analysis for Applications, New York: Academic Press.

Barreto, S., Ferreira, C., Paixao, J. ve Santos, B.S. (2007), Using Clustering Analysis in a Capacitated Location-Routing Problem. European Journal of Operational Research, 179, 968-977. Retrieved from https:/www.sciencedirect.com/science/article/abs/pii/S0377221706000786

Bano, S. ve Khan, M. N. A. (2018), A Survey of Data Clustering Methods. International Journal of Advanced Science and Technology, 113, 133-142.

Baygül, A. (2007), Kayıp Veri Analizinde S1klıkla Kullanılan Etkin Yöntemlerin Değerlendirilmesi, (Yüksek Lisans Tezi). İstanbul Üniversitesi Sağlık Bilimleri Enstitüsü, İstanbul.

Borah, B. ve Bhattacharyya, D.K. (2004), An Improved Sampling-Based DBSCAN for Large Spatial Databases. In Proceedings of International Conference on Intelligent Sensing and Information Processing, 92-96. Retrieved from https://ieeexplore.ieee.org/document/1287631

Bruzzone, L. ve Prieto, D. F. (2002), An Adaptive Semiparametric and ContextBased Approach to Unsupervised Change Detection in Multitemporal Remote-Sensing Images. IEEE Transactıons on Image Processing, 11(4), 452-466. Retrieved from http://eprints.biblio.unitn.it/113/1/30.pdf

Çakmak, Z. (1999), Kümeleme Analizinde Geçerlilik Problemi ve Kümeleme Sonuçlarının Değerlendirilmesi. Dumlupınar Üniversitesi Sosyal Bilimler Dergisi, 3, 187-205. Retrieved from https://birimler.dpu.edu.tr/app/views/ panel/ckfinder/userfiles/17/files/DERG_/3/187-206.pdf

Çelik, H.C. ve Kahyaoğlu, M. (2007), İlköğretim Öğretmen Adaylarının Teknolojiye Yönelik Tutumlarının Kümeleme Analizi. Türk Eğitim Bilimleri Dergisi, 5(4), 571-586. Retrieved from https://dergipark.org.tr/tr/download/articlefile $/ 256330$

Çelik, Ş. (2013), Kümeleme Analizi İle Sağlık Göstergelerine Göre Türkiye'deki İllerin Sınıflandırılması. Doğuş Üniversitesi Dergisi, 14(2), 175-194.

Doğan, N. ve Başokçu, T.O. (2010), İstatistik Tutum Ölçeği İçin Uygulanan Faktör Analizi ve Aşamalı Kümeleme Analizi Sonuçlarının Karşılaştırılması. Ĕ̌itimde ve Psikolojide Ölçme ve Değerlendirme Dergisi, 1(2), 65-71. Retrieved from https://dergipark.org.tr/en/ download/article-file/65985

Ersöz, F. (2009), OECD’ye Üye Ülkelerin Seçilmiş Sağl1k Göstergelerinin Kümeleme ve Ayırma Analizi ile Karşılaştırılması. Türkiye Klinikleri Tıp Bilimleri Dergisi, 29(6), 1650-1659.

Ester M., Kriegel H., Sander J., ve Xu X. (1996), A Density-Based Algorithm for Discovering Clusters in Large Spatial Databases With Noise. In Proc. 2nd Int. Conf. Knowledge Discovery and Data Mining (KDD’96), 226-231. 
Gökdalay, M. H. ve Evren, G. (2009), Havaalanlarının Performans Analizinde Bulanık Çok Ölçütlü Karar Verme Yaklaşımı. İTÜ Dergisi, 8(6), 157-168. Retrieved from https://docplayer.biz.tr/54458682-Havaalanlarininperformans-analizinde-bulanik-cok-olcutlu-karar-verme-yaklasimi.html

Han, J. ve Kamber, M. (2006), Data Mining: Concept and Techniques, USA: Morgan Kaufmann Publishers.

Henry, D.B., Tolan, P.H, Gorman-Smith, D. (2005), Cluster Analysis in Family Psychology Research. Journal of Family Psychology, 19(1), 121-132. Retrieved from https://www.ncbi.nlm.nih.gov/pubmed/15796658

Ho, T. K.,Hull, J.J. ve Sriharı, S.N. (1992), On Multiple Classifier Systems for Pattern Recognition. IEEE Int. Conference on Pattern Recognition (ICPR),1-5.

Jiang, D., Tang, C. ve Zhang, A. (2004), Cluster Analysis for Gene Expression Data: A Survey. IEEE Transactions On Knowledge and Data Engineering. 16(11), 1370-1386. Retrieved from https://ieeexplore. ieee.org/document/1339264

Karami, A. ve Johansson R. (2014), Utilization of Multi Attribute Decision Making Techniques to Integrate Automatic and Manual Ranking of Options. Journal of Information Science and Engineering, 30, 519-534. Retrieved from http://his.divaportal.org/smash/record.jsf?pid=diva2\% 3A1190675\&dswid $=1195$

Lansdowne Z.F. ve Woodward B.S. (1996), Applying the Borda Ranking Method. Air Force. Journal of Logistics, 20(2), 27-29. Retrieved from https://apps.dtic.mil/dtic/tr/fulltext/u2/a319245.pdf\#page=29

Malighetti, P., Paleari S. ve Redondi R. (2009), Airport Classification and Functionality Within The European Network. Problems and Perspectives in Management, 7, 183-196.

Sarıman, G. (2011), Veri Madenciliğinde Kümeleme Teknikleri Üzerine Bir Çalışma: K-Means ve K-Medoids Kümeleme Algoritmalarının Karş1laştırılması. Süleyman Demirel Üniversitesi Fen Bilimleri Enstitüsü Dergisi, 15(3), 192-202. Retrieved from https://dergipark.org.tr/tr/ download/article-file/193944

Servi, T. (2009), Çok Değiş̧kenli Karma Dağılım Modeline Dayalı Kümeleme Analizi, (Yüksek Lisans Tezi). Çukurova Üniversitesi Fen Bilimleri Enstitüsü, Adana.

Suman ve Rani, P. (2017), A Survey on STING and CLIQUE Grid Based Clustering Methods. International Journal of Advanced Research in Computer Science, 8(5), 1510-1512. Retrieved from https://search.proquest.com/openview/5be9b2f42d0417ecb52a9e4b4016bfbc /1?pq-origsite $=$ gscholar\&cbl $=1606379$

Tekbir, M. (2009), Aykırı Değer Tespitinde Yoğunluk Tabanlı Kümeleme Yöntemleri, (Yüksek Lisans Tezi). Yıldız Teknik Üniversitesi Fen Bilimleri Enstitüsü, İstanbul.

Tiryaki, S., Aydın, A. ve Üçüncü, K. (2015), Türkiye Mobilya Sektörünün Avrupa Birliği Sürecinde Dış Ticaret Durumunun Kümeleme Analizi İle İncelenmesi. Selçuk Teknik Dergisi, Özel Sayı-1 (UMK-2015), 938-949. Retrieved from http://sutod.selcuk.edu.tr/sutod/article/view/270/239 
EM Algoritmasına Göre Kümelenen Havalimanlarının Borda Sayım Yöntemi İe Değerlendirilmesi

Tola, V., Lillo, F., Gallegati, M. ve Mantegna, R.N. (2008), Cluster Analysis For Portfolio Optimization. Journal of Economic Dynamics and Control, 32, 235 258. Retrieved from https://arxiv.org/pdf/physics/0507006.pdf

Top, E. D., Yapıcı, N. ve Çetinkaya, Ç. (2018), Comparison of Fatal Occupational Accidents Statistics in Turkey with Some European Countries. International Journal of Scientific and Technological Research, 4(6), 107-119. Retrieved from https:/www.researchgate.net/ profile/Nil_Yapici/publication/ 325269853_Comparison_of_Fatal_Occupational_Accidents_Statistics_in_T urkey_with_Some_European_Countries/links/5bdי_b090892851c6b279e-4c $\overline{5}$ b/ Comparison-of-Fatal-Occupational-Accidents-Statistics-in-Turkey-withSome-European-Countries.pdf

Turan, F. ve Turan, S. K. (2008), Havaalanlarının Sosyal Etkileri: Sabiha Gökçen Havaalanı Örneği. Anlara Üniversitesi, Türkiye Coğrafyası Araştırma ve Uygulama Merkezi, 5. Ulusal Coğrafya Sempozyumu, 161-166.

Turanlı, M., Özden, Ü.H. ve Türedi, S. (2006), Avrupa Birliği’ne Aday ve Üye Ülkelerin Ekonomik Benzerliklerinin Kümeleme Analiziyle İncelenmesi. Istanbul Ticaret Üniversitesi Sosyal Bilimler Dergisi, 5(9), 95-108. Retrieved from http://acikerisim.ticaret.edu.tr/xmlui/bitstream/handle/ 11467/891/M01135.pdf?sequence=1\&isAllowed=y

Wang, T. C. ve Lee, H. D. (2009), Developing a Fuzzy TOPSIS Approach Based on Subjective Weights and Objective Weights. Expert Systems with Applications, 36, 8980-8985. Retrieved from http://ir.lib.kuas.edu.tw/bitstream/987654321/ 13826/2/Developing+a+fuzzy+TOPSIS+approach+based+on+subjective.pdf

Wu, W. W. (2011), Beyond Travel \& Tourism competitiveness ranking using DEA, GST, ANN and Borda Count. Expert Systems with Applications, 38, 1297412982. Retrieved from https://www.sciencedirect.com/ science/article/pii/S0957417411006233

Yalçın, S. ve Ayyıldız, E. (2018), Analysis of Airports Using Clustering Methods: Case Study In Turkey. Journal of Management Marketing and Logistics, 5(3), 194-205. Retrieved from https://dergipark.org.tr/tr/ download/articlefile/551606

Ye, Q., Gao, W. ve Zeng W. (2003), Color Image Segmentation Using Density-Based Clustering. In Proc. Int. Conf. Acoustics, Speech and Signal Processing, Hong Kong, 345-348.

Zhang, H., Gu, C. L., Gu, L. W. ve Zhang, Y. (2011), The Evaluation of Tourism Destination Competitiveness By Topsis \& Information Entropy-A Case In The Yangtze River Delta of China. Tourism Management, 32(2), 443-451. https:/www.sciencedirect.com/science/article/abs/pii/S0261517710000415 